University of Massachusetts Amherst

ScholarWorks@UMass Amherst

Spring August 2014

\title{
THE EFFECTS OF AN AUDITOR'S COMMUNICATION MODE AND PROFESSIONAL TONE ON CLIENT RESPONSES TO AUDIT INQUIRIES
}

Aaron Saiewitz

University of Massachusetts Amherst

Follow this and additional works at: https://scholarworks.umass.edu/dissertations_2

Part of the Accounting Commons

\section{Recommended Citation}

Saiewitz, Aaron, "THE EFFECTS OF AN AUDITOR'S COMMUNICATION MODE AND PROFESSIONAL TONE ON CLIENT RESPONSES TO AUDIT INQUIRIES" (2014). Doctoral Dissertations. 146.

https://doi.org/10.7275/8bvd-5081 https://scholarworks.umass.edu/dissertations_2/146

This Open Access Dissertation is brought to you for free and open access by the Dissertations and Theses at ScholarWorks@UMass Amherst. It has been accepted for inclusion in Doctoral Dissertations by an authorized administrator of ScholarWorks@UMass Amherst. For more information, please contact scholarworks@library.umass.edu. 
THE EFFECTS OF AN AUDITOR'S COMMUNICATION MODE AND

PROFESSIONAL TONE ON CLIENT RESPONSES TO AUDIT INQUIRIES

A Dissertation Presented

by

AARON SAIEWITZ

Submitted to the Graduate School of the

University of Massachusetts Amherst in partial fulfillment

of the requirements for the degree of

DOCTOR OF PHILOSOPHY

May 2014

Isenberg School of Management 
(C) Copyright by Aaron Saiewitz 2014

All Rights Reserved 
THE EFFECTS OF AN AUDITOR'S COMMUNICATION MODE AND

PROFESSIONAL TONE ON CLIENT RESPONSES TO AUDIT INQUIRIES

\author{
A Dissertation Presented
}

by

AARON SAIEWITZ

Approved as to style and content by:

Thomas Kida, Chair

Christopher P. Agoglia, Member

M. David Piercey, Member

G. Bradley Bennett, Member

Linda M. Isbell, Member

George R. Milne, Ph.D. Program Director

Isenberg School of Management 


\section{DEDICATION}

For my wife, Karen, and for my children, Matthew and Sarah. 


\section{ACKNOWLEDGMENTS}

I would like to thank Tom Kida for all his advice and for his great sense of humor.

I joked once that Tom must love those moments when his doctoral students come to the same conclusion he had two months earlier. I appreciate that he rarely provides the answer, allowing his students to learn for themselves, but I've learned that if Tom is concerned about something there’s probably a very good reason! I also admire Tom’s ability to laugh at himself, the mark of a good person. Importantly, I thank him for not kicking me out of the program when my Giants defeated his beloved Patriots in the Super Bowl for a second time. In all seriousness, though, one of the best moments of my entire program was when Tom said "I like that!" to this idea. I consider myself very fortunate to have him as my advisor and friend.

I can’t thank my committee members enough for their insight and support. Thanks to Dave Piercey for the wealth of knowledge he shared on theory and statistical analysis, to Chris Agoglia for his support of "DV1" and his help in fashioning "the story,” and to Bradley Bennett for sharing his recent dissertation experience and for looking at an early draft I wouldn’t dare show to the senior members of the committee! Last, but not remotely least, thanks to my “outside” member Linda Isbell, who spent as

much time with me (if not more) as nearly all of my "inside” members. I appreciate your enthusiasm for the project, as well as your intellectual support and all the pep-talks.

My fellow accounting doctoral students at UMass have been a huge source of support, assistance, and friendship. Thanks to Ryan for all your thoughts, advice, and general commiseration, to Mary Kate and Jess for your awesome coding efforts and your 
positive attitudes, to Steve and Jeff for listening to me rant and giving me feedback, and to Elisa for help with the filming. Also, thanks to Steve's brother John for taking the starring role and to my nephew Adam who helped with editing. Thanks also to Pam Trafford, Susan Machuga, and Tom Moliterno for providing the experienced professionals and Chetan Chawla and Jeff Gauthier for providing the undergraduate participants. Particular thanks go to Steve Perreault and Roger Silvers for all their guidance and friendship throughout the course of my doctoral program. Additionally, I have to acknowledge my extended family of doctoral students who have become great friends, including Spencer Ross, Delancy Bennett, Derek Tan, Kunal Swani, Rory Eckardt, and many others. You've all made UMass a home for the last four and a half years and I will always remember our time here with a smile.

I also need to thank my family and friends "back home” for all their support, particularly my parents who have visited us often and opened their home to us on so many trips back to NJ. Your love and support has meant so much to us. Thanks also to my brothers and my sister for continuing to give me great life advice, and to Karen's grandmother Tillie and cousins Carol and Ted for your continued support and belief in us. Also, thanks to all my friends, family, colleagues, and clients who did not think I was insane to give up my position as a partner to pursue a career in academia. Everyone knew this was the right path for me, and that support made this an easy decision, one I have yet to regret for a moment.

Finally and by far most importantly, my love and thanks to my children and my wife. My son Matthew makes me proud nearly every day with how smart and funny he is. As her favorite pair of PJs state, my daughter Sarah truly has me under her spell. She can 
always make me smile and laugh, no matter how rough a day I've had. I love you both more than words can ever say. And, to Karen, thanks for letting me upend our lives to pursue this dream. I think we're both happier for it, but I could never have done this without your support and sacrifice. I am truly the lucky one, and can never thank you enough for being such a wonderful wife, mother, and friend. 


\begin{abstract}
THE EFFECTS OF AN AUDITOR'S COMMUNICATION MODE AND PROFESSIONAL TONE ON CLIENT RESPONSES TO AUDIT INQUIRIES
\end{abstract}

MAY 2014

\title{
AARON SAIEWITZ, B.S., FAIRLEIGH DICKINSON UNIVERSITY Ph.D., UNIVERSITY OF MASSACHUSETTS AMHERST
}

Directed by: Professor Thomas Kida

Recent audit research has indicated that junior auditors tend to use e-mail for client inquiries. Additionally, audit firms have expressed concerns regarding the ability of junior auditors to communicate professionally. In this study, I investigate whether receiving an auditor inquiry via e-mail differentially affects client responses as compared to more traditional modes of inquiry and whether those responses are affected by the auditor's professional tone. In an experiment, experienced business professionals respond to a request for information from an auditor regarding a potential accounting adjustment. I varied the communication mode of the request (e-mail, audio, or visual) and the professional tone of the communication (more vs. less professional tone) and then measured the extent to which participants revealed information that either supported or did not support the client's accounting position. I find that an auditor e-mail inquiry results in client responses that are more biased towards items that support the client's position as compared to audio or visual inquiries. In addition, I find that clients respond in a more biased manner when the inquiry is worded in a less professional tone as compared to a more professional tone and that this tendency may be exacerbated when they receive the request via e-mail. Further underscoring the implications of these 
findings for audit outcomes, I find that clients are less likely to agree with an auditor's proposed income-decreasing adjustment if the client did not personally reveal applicable information to the auditor. 


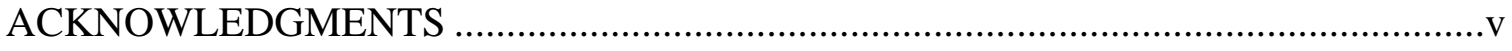

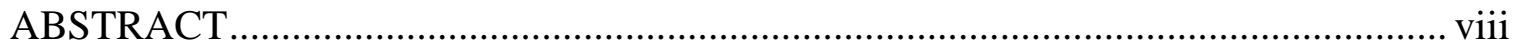

LIST OF TABLES ........................................................................................... xii

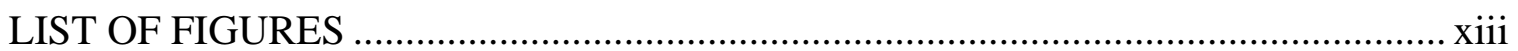

\section{CHAPTER}

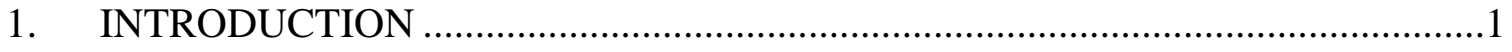

Communication Mode ..............................................................................

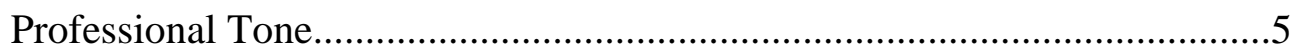

Agreement with Auditor's Proposed Adjustment............................................

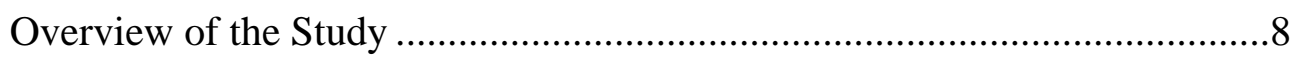

Preview of the Results .................................................................................

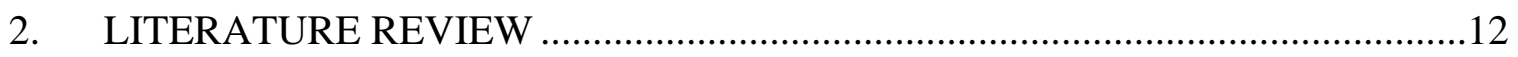

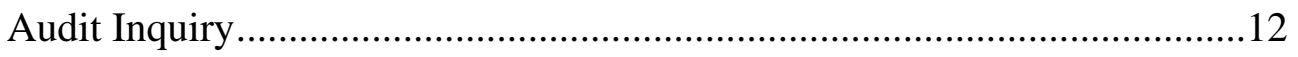

Communication Mode ..................................................................................14

Defensive Bolstering........................................................................18

Professional Tone.......................................................................................20

Norm Violations.............................................................................22

Client Agreement with Auditor Adjustments ................................................24

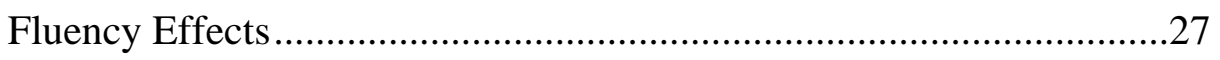

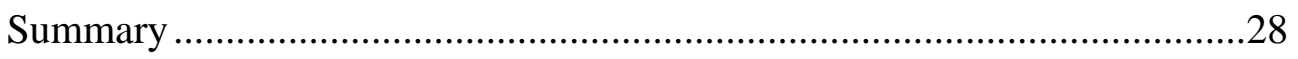

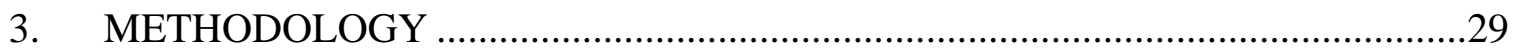

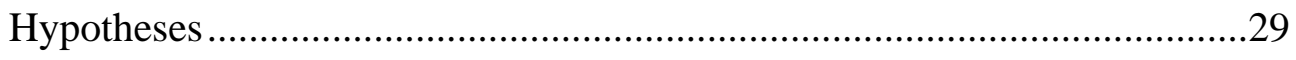




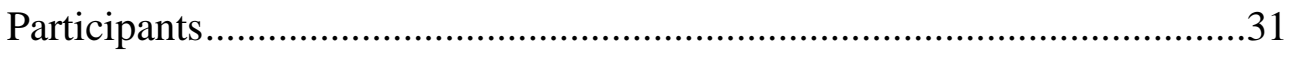

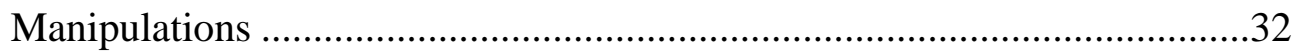

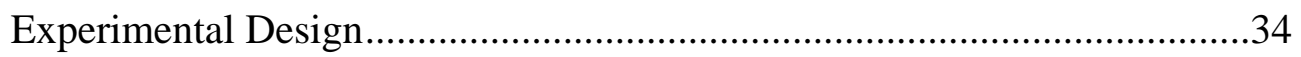

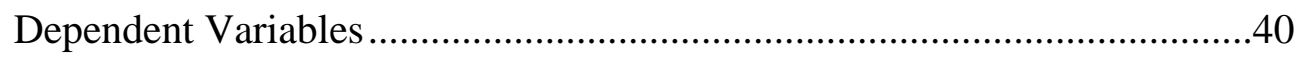

Net Items Revealed .................................................................40

Measures of Agreement with Proposed Audit Adjustment...................41

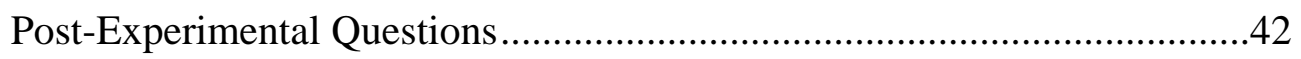

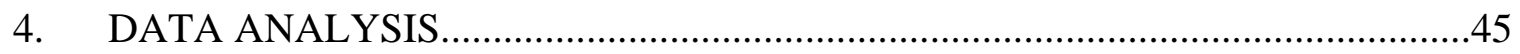

Analysis of Client Responses to Auditor Request .....................................45

Salience of Professional Tone Manipulation ............................................50

Client Agreement with Proposed Adjustment ...........................................55

Supplementary Analyses................................................................60

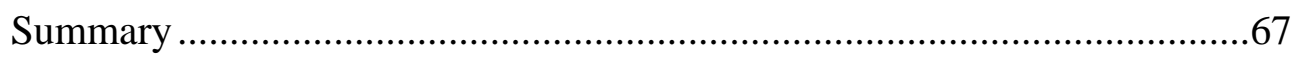

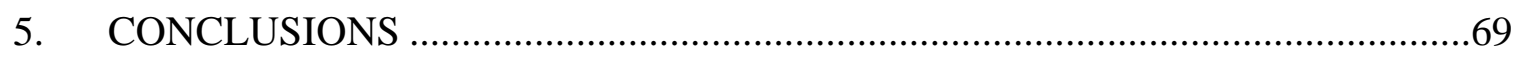

Limitations and Future Research ...................................................... 70

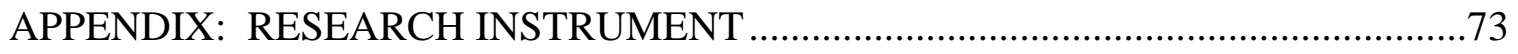

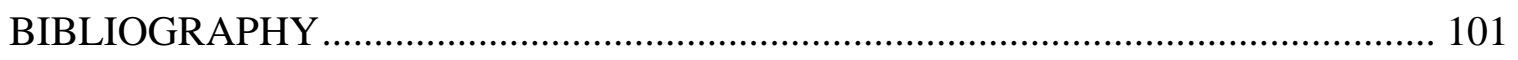




\section{LIST OF TABLES}

Table

3.1 Wording of Professional Tone Manipulation ...... .35

3.2 Inventory Related Items in Experiment ........................................................38

4.1 Net Items Revealed by Client in Response to Auditor Inquiry ..............................46

4.2 Client Agreement with Auditor’s Proposed Write-down .....................................58

4.3 Responses to Post-Experimental Questions.......................................................61 


\section{LIST OF FIGURES}

Figure

Page

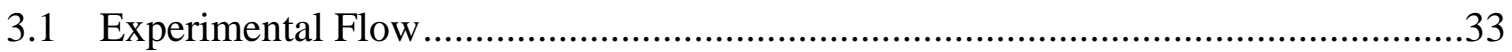

4.1 Net Items Revealed by Clients in Response to Auditor Inquiry .............................48

4.2 Client Perceptions of the Professionalism of the Auditor's Inquiry ........................51

4.3 Net Items Revealed by Clients in Response to Auditor Inquiry - Study 2 ...............54

4.4 Client Perceptions of the Professionalism of the Auditor's Inquiry - Study 2 .........56 


\section{CHAPTER 1}

\section{INTRODUCTION}

In recent years, audit firms have become concerned about the propensity of junior auditors to use e-mail for communication with client personnel (May and May 2012). “Millennials” (those born since 1980) have grown up utilizing computer-based communication technology and are often most comfortable with sending abbreviated, text-based messages (Lancaster and Stillman 2010). In addition, recent research in the auditing literature demonstrates that younger professionals use e-mail for client inquiries in order to avoid uncomfortable interactions with more senior client personnel (Bennett and Hatfield 2013).

Messier et al. (2012) note that auditors discover a great deal of information via direct inquiry with client personnel. Trompeter and Wright (2010) confirm that client inquiry is a frequently-used method for gathering information regarding unusual fluctuations and potential risk areas. They further note that client inquiry is often conducted by lower-level staff. While younger professionals may be more comfortable with using e-mail to inquire with client personnel (Bennett and Hatfield 2013), no prior research has considered whether there are adverse effects on client responses to e-mail inquiries.

Another concern regarding the client inquiry process is that junior auditors may lack appropriate professional communication skills (Jackson 2012; Jones 2011). Experienced business professionals consider it important to use an appropriate tone in a professional business context (Jones 2011). However, communicating in a professional 
tone is an acquired skill that many professionals may lack at the beginning of their career (Dixon et al. 2010; Calvert and Kurji 2012).

The purpose of this study is to investigate how an auditor's choice of communication mode for client inquiries affects the content of the client's response, as well as whether client responses can be affected by the professional tone of the inquiry. I also investigate whether a client's subsequent agreement with a proposed audit adjustment can be affected by the client's earlier response to the audit inquiry.

\section{Communication Mode}

Prior audit research indicates that electronic communication can have both beneficial and detrimental effects. Bennett and Hatfield (2013) find that junior staff auditors are more likely to request information from senior clients if the junior auditors are allowed to use e-mail for the request, as opposed to having to make a face-to-face (F2F) request, since e-mail allows the junior auditors to avoid uncomfortable social interactions with more senior clients. Additionally, Lynch et al. (2009) find that brainstorming sessions held in an electronic format lead to an increase in the number of relevant fraud risks identified when compared to F2F brainstorming. On the other hand, Brazel et al. (2004) demonstrate that auditors who anticipate F2F review exert more effort and are more effective than those who expect e-review or no review. They suggest that their results are due to increased perceptions of accountability when anticipating F2F review.

While the above research has considered the effects of different modes of communication on auditor performance, no research has considered the impact of these 
choices on client responses. This aspect is important because there are audit situations in which inquiry reveals previously unknown information (Messier et al. 2012; Trompeter and Wright 2010). While Bennett and Hatfield's (2013) finding that younger staff auditors are more willing to ask for additional information via e-mail suggests a benefit of e-mail use for audit inquiries, if client personnel react in a biased manner to ecommunication, the benefit may be eliminated or may be negative overall, ultimately affecting audit outcomes.

A biased reaction may arise as a result of defensive bolstering, a process in which individuals feel compelled to defend a position to someone whom they feel accountable (Tetlock et al. 1989). In an audit context, a client likely feels accountable to an auditor while at the same time the client has an incentive to maintain commitment to their preexisting accounting positions, with the knowledge that the auditor is typically seeking a more conservative position (i.e., typically income-reducing). Accordingly, the client may feel compelled to defend their position and may bias their responses by revealing more information that supports their position and/or less information that does not support their position (cf. Chaiken et al. 1996).

Defensive bolstering may be more pronounced in response to an e-mail inquiry as compared to an audio or visual inquiry. Suh (1999) notes that audio and visual communications include more cues than written communications, including nonverbal cues such as body-language and physical appearance, as well as vocal inflection. Defensive bolstering is an effortful process that generally requires that the individual has the capacity to engage in systematic processing (Chaiken et al. 1996; Eagly 2007). The additional cues present in an audio or visual interaction can be distracting (Suh 1999) and 
can therefore result in a taxing of cognitive resources (cf. Ferran and Watts 2008; Sussman and Siegal 2003), reducing the ability to engage in defensive bolstering. In addition, Swaab et al. (2012) note that audio and visual interactions involve greater social presence than e-communication, leading to greater cooperation and information sharing between negotiating parties. When a party is less cooperative, they are more likely to withhold information that can aid the other party. Accordingly, social presence theory (Short 1974; see also Elliott et al. 2012) would lead to similar predictions. Based on these theories, F2F and phone inquiries should result in client responses that are not as heavily weighted towards information that supports a client's position as compared to an e-mail.

E-mail represents a relatively recent innovation for client inquiry, and I propose that e-mail requests lead to more biased responses from clients as compared to requests using more traditional modes of communication (e.g., F2F and phone). Of course, client inquiries may be made by any of these methods. As a result, I also investigate whether an audio-only request leads to any difference from a visual request. Prior research suggests that additional cues found in visual communication may become distracting. Suh (1999) finds that in some situations phone can lead to better outcomes than F2F because individuals focus more on the task than the appearance of the sender. Alternatively, increased social presence in a F2F context may lead to superior outcomes as compared to a phone context (Short 1974). Further, Daft and Lengel (1986) suggest there may be no difference for a relatively simple request. Accordingly, it is unclear whether responses to F2F and phone requests will differ, and I explore the possibility in this study. 


\section{$\underline{\text { Professional Tone }}$}

Professionalism is a fairly broad construct (Carr and Stefaniak 2012). Cheney and Ashcraft (2007) describe many variations of the term "professional" in both research and popular culture. One aspect they describe is the need to perform in a manner that implies rationality rather than emotionality including, in an extreme example, suppressing spontaneity and individuality. Kramer and Hess (2002) discuss that acting professional often requires acting in a manner different from social, non-professional situations. In general, Cheney and Ashcraft (2007) note that professionalism can serve to subjugate individuals to established, dominant norms. As such, use of a less professional tone may be viewed by experienced professionals as norm-violating.

Consistent with this, Carr and Stefaniak (2012) find that professional tone in email communications has an effect on perceptions of credibility. They note that “managers consider basic writing mechanics an essential job skill, even more so than most computer competencies in increasingly wired organizations.” Jessmer and Anderson (2001) find that e-mail senders who are impolite or use poor grammar are viewed as less competent than those who are polite and use proper grammar. Regarding specific professional behavior, Waner (1995) found that business professionals believe that using an appropriate tone of voice for the context is a very important interpersonal skill. Recently, Jones (2011) found that accounting managers rate "appropriate level of tone and formality” in communications as very important. In addition, they generally are not satisfied with staff accountants’ performance in this area. Compounding this problem, older firm personnel believe, and research confirms, that younger staff overestimate their communication skills, both written and oral (Ernst \& Young 2008; Jackson 2012). 
Research into the effects of norm violations suggests that experienced professionals may have aversive reactions to a violation of professional communication norms. Cialdini and Goldstein (2004) suggest that willingness to comply with a request could be affected by whether the request is norm-violating. In addition, Brauer and Chekroun (2005) note that a negative response to a norm violation could be an expression of social control, in which the perceiver expresses disapproval in response to a norm violation. This does not necessarily need to be a direct reprimand, but could instead be an aversive reaction (Brauer and Chekroun 2005). In effect, if a young auditor communicates in a less professional tone, this norm violation may cause the client to become less cooperative and, therefore, reveal less information that is beneficial to the auditor's goals (i.e., the client may provide a response set that is more biased towards the client's position).

While the effects for professional tone can occur in any type of communication mode, it may be more pronounced for an e-mail inquiry. Individuals may pay closer attention to the wording used in an e-mail than in a spoken conversation because e-mails do not have visual cues or vocal inflection cues that could distract the individual (Cheshin et al. 2011; Suh 1999). In addition, individuals may be more willing to accept a less professional conversational tone with phone or F2F communication because these modes are, by their nature, conversational. As a result, it is not unreasonable to expect that the effects for professional tone may be exacerbated for e-mail inquiry and attenuated for audio and visual inquiry, although the extent of such exacerbation and attenuation is unclear. 


\section{$\underline{\text { Agreement with an Auditor's Proposed Adjustment }}$}

Trompeter and Wright (2010) raise concerns regarding whether auditors adequately search for corroborating evidence based on client responses to auditor inquiries. In particular, they note that auditors may focus on confirming evidence and may not adequately search for disconfirming evidence. Therefore, if a client provides a response that is more biased towards items that support their position, auditors may inadequately search for contradictory evidence and could fail to uncover the issue. Of course, inquiry is not the only audit technique used to uncover information. The relevant issues could be uncovered via alternative procedures such as tests of transactions and balances, analytical procedures, reading industry and economic news, and even inquiries with other personnel. However, there are many scenarios in which inquiry would be a likely way to learn of an issue, including inventory obsolescence and contingent liabilities. Alternatively, even if the staff auditor fails to uncover the issue, it is possible that it could be unearthed during the review process. However, the staff auditor may stylize the documentation of the client response in a manner that makes it more difficult for the reviewer to determine that the interaction between the auditor and the client was inadequate (Ricchiute 1999; Yip-Ow and Tan 2000; Bennett and Hatfield 2013).

To investigate whether communication mode and professional tone could have an overall effect on audit outcomes even if the issue is discovered via alternative procedures, I also investigate whether the extent of bias in a client's response affects their willingness to agree with an auditor's proposed income-decreasing adjustment to the financial statements. Information that the client has personally revealed to the auditor should be more familiar to the client. Claypool et al. (2004) demonstrate that information that has 
greater familiarity and more personal relevance is more likely to be accepted by an individual (see also Garcia-Marques and Mackie 2001). Accordingly, I expect that agreement with a proposed adjustment will be affected by the degree to which the auditor's justification for the adjustment derives from information provided by the participant in their response to the first request.

\section{Overview of the Study}

In this study, experienced business professionals, most with managerial experience, assumed the role of a client manager who receives an inquiry related to a potential inventory obsolescence problem. The request was either presented in the form of an e-mail, an audio-only request, or a visual request, and the wording of the inquiry was either more or less professional in tone.

Participants were asked to respond to the inquiry based on previously provided background information. Included in this information were nine items that supported the client's position of no inventory obsolescence, and nine items that did not support that position and, in fact, suggested that there was an obsolescence problem. With the assistance of two independent coders, the responses were analyzed to determine which items of information the participants revealed. The main dependent variable analyzed was the net number of items revealed that supported a write-down of inventory less the number of items revealed that did not support a write-down. As such, a lower value of net items revealed indicated a response that was more biased towards items that support the client's position that no write-down is necessary. 
After providing their responses, participants were told that the audit team has determined that there is an inventory obsolescence problem and the auditors are proposing a material write-down of the inventory value. Participants were then asked how strongly they agree or disagree with the auditor's proposed adjustment, whether they would accept the adjustment outright and, if not, the amount they think the company should counterpropose, as well as the maximum acceptable adjustment.

After completing the experimental tasks, participants were asked several questions related to their reactions to, and impressions of, the junior auditor and the entire audit team. They were then asked several questions related to experience with technology and their attitudes regarding several technology and communication issues, as well as questions related to attitudes regarding power distance (House et al. 2004). Finally, participants provided demographic data, including age, gender, and years of business and managerial experience.

\section{Preview of the Results}

I find that participants provide responses that are more biased towards items that support their position when receiving an e-mail request than when receiving an audio or visual request. In addition, participants provide responses that are more biased towards items that support their position when receiving a less professionally vs. a more professionally worded inquiry. The results suggest that the effect of a less professional tone may be exacerbated in response to an e-mail and/or attenuated in response to audio or visual inquiries. Supplemental analysis reveals that the effect of professional tone on bias in the client's response is mediated by perceptions of the professionalism of the 
auditor's request, but only in the e-mail condition, suggesting the norm violation only triggers a response when salient. Further, an additional study comparing experienced business professionals and senior undergraduate business majors reveals that the difference in professionalism was only perceived by the experienced participants and, accordingly, only the experienced participants had responses that were more biased towards items that supported their position when receiving a less professionally worded request as compared to a more professionally worded request. Finally, I find that clients are less likely to agree with an auditor's proposed income-reducing adjustment if the client previously provided a response that was more biased towards items that support their position.

This research has implications for both practice and theory. From a practice standpoint, my findings provide evidence that communication mode and the professionalism of the communication can have ramifications for audit outcomes. In particular, the trend of young auditors using e-mail for client inquiries increases the likelihood that clients will provide an information set more biased towards items that support the client's position. This has several implications for the audit process. As mentioned above, Trompeter and Wright (2010) note that inquiry is often a prominent source for investigating potential audit issues. Further, they note a concern regarding whether auditors adequately corroborate client responses to audit inquiries and, in particular, whether auditors adequately seek disconfirming evidence. Accordingly, if clients provide biased responses, Trompeter and Wright's (2010) findings suggest that auditors may fail to discover disconfirming evidence, suggesting that the biased responses found in my study could impact audit outcomes. Additionally, my finding that 
clients who provide more biased responses are less likely to agree with an auditor's proposed income-decreasing adjustment and plan to negotiate more aggressively with the auditor is important because prior research shows that this resistance could result in a less conservative adjustment (cf. Hatfield et al. 2010; Brown-Liburd and Wright 2011). Accordingly, the factors investigated in my study may have an effect on audit outcomes even if the issues are uncovered via alternative means such as tests of transactions and balances, reading industry and economic news, or even inquiries with other personnel. With respect to theory, this study provides evidence on the relationship of mode of communication and defensive bolstering, and also suggests that an aversive reaction to professional norm violations could include increased defensive bolstering. 


\section{CHAPTER 2}

\section{LITERATURE REVIEW}

In this chapter, I first review the literature on the audit inquiry process. I then review relevant literature related to communication mode and professional tone. I also provide an overview of research investigating the client side of auditor-client negotiations. Where applicable, I provide an overview of relevant psychological theories.

\section{Audit Inquiry}

Audit inquiry refers to an auditor requesting information directly from a client or asking questions about events related to the period under audit. For example, an auditor may ask for explanations regarding unusual or unexpected relationships noted in analytical procedures, or an auditor may inquire about the effects of certain economic events. Of course, inquiry by itself is generally not sufficient audit evidence. At least on a test basis, auditors should vouch and trace source documents, observe and inspect documents and physical assets, and observe and reperform client procedures. However, Messier et al. (2012) note that a great deal of information is discovered by auditors via direct inquiry with client personnel. Audit executives have confirmed that often they discover issues simply by talking with clients. ${ }^{1}$

Further, Trompeter and Wright (2010) note that inquiry is the most commonly used method to initially investigate significant or unusual fluctuations in analytical procedures. Trompeter and Wright (2010) interviewed 36 auditors of varying levels and

\footnotetext{
${ }^{1}$ Audit executives have stated this in various panel sessions at American Accounting Association meetings. Additionally, I was told this directly by several audit executives in personal conversations.
} 
found that $86 \%$ stated that the first step they take in response to unexpected differences found in analytical procedures is to ask the client for an explanation. ${ }^{2}$ In addition, a disconcerting finding was that $31 \%$ of interviewees did not indicate searching for corroborating evidence. Further, the interviewees indicated that they are only searching for disconfirming evidence $28 \%$ of the time, indicating that the majority of the time they are searching only for confirming evidence. This confirmation bias regarding client responses to audit inquiries echoed earlier findings by Hirst and Koonce (1996), who also interviewed auditors of varying levels. In many of their interviews, auditors talked about inquiring with clients for explanations to unusual fluctuations in substantive analytical procedures. In those cases, all of the auditors indicated that they primarily searched for corroborating evidence. Hirst and Koonce point out that the auditors "also noted that they do not normally seek information that contradicts or refutes explanations, unless information comes to their attention indicating an explanation may not be valid” (p. 474). Based on this, and based on Trompeter and Wright's (2010) consistent finding, a concern arises that if an auditor seeks an explanation from a client and the client responds in a manner that is biased away from disconfirming items, the auditor may fail to adequately seek disconfirming evidence.

There are a limited number of studies that have investigated the effects of audit inquiry, and none to my knowledge have tested ways to alter inquiry to improve the degree to which clients reveal information to the auditors. Kaplan et al. (2011) conducted an experiment in which one of the factors investigated was the presence or absence of an

\footnotetext{
${ }^{2}$ When asked "When would you not ask a client for an explanation?”, $61 \%$ of the interviewees said "never or rarely," $31 \%$ said that they would instead first generate their own explanations, and 22\% said that they would not go to the client if fraud was suspected.
} 
inquiring auditor. They found that managers were more likely to report fraud when an auditor asked if the participant was aware of any fraud (as required by SAS No. 99). Specifically, the results indicated that the participants were significantly more likely to intend to report a fraud in the presence of an inquiring auditor than a non-inquiring auditor. ${ }^{3}$ Other studies of the auditor-client inquiry process have primarily focused on the auditor's side of the inquiry process. Lee and Welker (2007) use students to proxy for entry-level auditors and find that students are unable to identify fraud via inquiry, even after training in inquiry methods. Liu (2012) looks at how certain decision aids can improve the way in which staff auditors plan to conduct client inquiries.

In summary, the literature suggests that inquiry is commonly used, and is sometimes a primary vehicle for discovering information from the client. In particular, concerns arise regarding whether auditors adequately corroborate information discovered during client inquiry and, in particular, whether they adequately search for disconfirming evidence. Prior research has primarily focused on the auditor side of the inquiry process, and very little research has investigated how to obtain a more useful information set from clients via inquiry.

\section{Communication Mode}

Prior research into the effects of different modes of communication has often centered around normative theories (Postmes et al. 2000). Daft and Lengel (1986) proposed Media Richness Theory (MRT) which posits that media "richness," i.e., the

\footnotetext{
${ }^{3}$ The dependent variable in Kaplan et al.'s (2011) study was intention to report, rather than an actual action to report. Sheeran (2002) conducted a meta-analysis of research looking at the correlation of intentions and actions, finding a fairly high correlation ( $\mathrm{r}=.52)$. My dissertation looks at actual reporting actions by clients, rather than reporting intentions.
} 
depth of its cues, the degree to which it can be reprocessed, and the speed at which feedback occurs (“synchronicity”), guides both choice to utilize a particular communication media and qualities of outcomes related to the choice of media. The communication mode with the greatest richness would be face-to-face interaction, followed by video-conferencing, telephone conversations, direct written communications (which would include e-mail), and general publications (e.g., a report that is not specific to an individual or organization). Under MRT, richer media leads to lower degrees of equivocality and is best when overall task ambiguity is high. When task ambiguity is low, media that is low in richness should be adequate under MRT, particularly when the task lacks complexity (Daft and Lengel 1986).

However, while MRT has been extensively applied in the literature, support has been mixed or poor (Suh 1999; King and Xia 1997). A common criticism of MRT is that it represents a normative, rational model that does not take into account social psychological influences (Fulk et al. 1987; Kock 2005). Fulk et al. (1987) criticize MRT's implication that modes of communication have certain objective characteristics, e.g., richness, synchronicity, and so forth, and that these characteristics are invariant to users' subjective views or social contexts. To address this perceived shortcoming, Fulk et al. proposed a social information processing theory (SIPT) of media use that suggests meaning is "socially constructed” and that "perceived properties vary by user and social context of use” (Fulk et al. 1987). Fulk et al. note that MRT also suggests that the objective properties of different forms of media are equally salient to all users and that user choice of media is the result of an "objectively rational” decision process. With social information processing theory, Fulk et al. (1987) state that saliency is affected by 
social cues from others and that media choices are "retrospectively and subjectively rational.”

Recently, Swaab et al. (2012) have proposed a communication model that incorporates MRT, SIPT, and Social Presence Theory (Short 1974). This model suggests that communication modes with greater levels of social presence (i.e., awareness that a human being is making the request) will lead to more cooperation when the content of the communication is consistent with the recipient's aims, but will lead to less cooperation vs. communication modes that involve less social presence (e.g., e-mail) when the content is detrimental. Further, common social categories will lead to more cooperation, while different social categories will lead to less cooperation. Finally, under this model, when a pre-existing cooperative social relationship exists, communication mode may not have a differential effect on negotiation outcomes or group decision tasks. ${ }^{4}$ Swaab et al. conducted a meta-analysis of communication studies to support this model.

In the auditing literature, Nöteberg, Benford, and Hunton (2003) proposed a media task-fit model for auditor-client interactions based on MRT, in which rich media is necessary only when the task demands higher richness (e.g., a task with high ambiguity). To test this model, Nöteberg and Hunton (2005) conducted an experiment in which auditors received an explanation for an audit issue and then measured the degree to which the auditors accepted the client's explanation. They find that auditors pay closer attention to a client's explanation in e-mail form and are more accepting of the client's argument

\footnotetext{
${ }^{4}$ This current study does not investigate the effects of a pre-existing relationship. Bennett and Hatfield (2013) would suggest that junior auditors do not typically develop a close relationship with more senior clients, particularly as they may feel intimidated by more senior clients. Future research can investigate the effects of social relationship on a client's propensity to reveal information to an auditor, as well as effects on the auditor's professional skepticism.
} 
compared to F2F, although in their experiment the opposite occurred when participants had repeated exposure to the message, suggesting that repeated F2F persuasion attempts may lead to greater acceptance of client arguments vs. repeated attempts via e-mail. ${ }^{5}$

Bennett and Hatfield (2013) conducted an experiment in which graduate level auditing students proxied for new staff auditors and were required to use either e-mail or F2F to inquire with a senior client or a younger client, played by confederates. Their study revealed a benefit of e-mail use in that participants were more likely to ask for additional information from the client if they were able to do so in e-mail rather than F2F. This did not fully eliminate the negative effects of a junior auditor interacting with a senior client, but it was beneficial.

All other communication mode research in auditing has looked at the effects of different communication modes within audit teams. Brazel et al. (2004) examined the effects of anticipating electronic review (e-review) vs. F2F review. Participants were told that they would be reviewed either via e-mail or in a F2F meeting. Participants in the ereview condition exerted less effort and were less accurate in their documentation as opposed to those in the F2F condition. E-review results did not statistically differ from a control condition in which the participants were not told to expect any review. Brazel et al. suggest that anticipation of F2F review leads to stronger feelings of accountability and

\footnotetext{
${ }^{5}$ In a study that investigates differences in investment decisions based on receiving a restatement announcement via video or text, Elliott et al. (2012) find that when a CEO offers an internal attribution for the restatement (i.e., accepts responsibility), social presence in a video leads to greater trusting by the investors as compared to a text-only announcement. In contrast, when the CEO blames external factors for the restatement, the opposite occurs and social presence in the video leads to lower levels of trust and lower willingness to invest compared to a text announcement. This is not inconsistent with Nöteberg and Hunton (2005) who suggest that peripheral cues in their study may have conflicted with the message (e.g., the client looked very professional and organized, yet provided a weak argument). This contradiction of peripheral (nonverbal) and central (wording) cues led to greater rejection of the client's argument vs. a textonly explanation (although only when there was no repeat exposure), comparable to Elliott et al.'s (2012) finding that denial of responsibility led to less trust and lower investment decisions in response to a video vs. a text-only announcement.
} 
therefore greater effort occurs. In a study of auditor brainstorming teams, Lynch et al. (2009) find that electronic brainstorming leads to identification of more relevant fraud risks as compared to F2F brainstorming. They posit that this is because of a reduction in production blocking.

In summary, the general communications literature is still debating the appropriateness of various models of communication mode use and effects. The auditing literature has not deeply investigated the effects of communication modes, but research to date has shown that in some situations, electronic communication can be beneficial (e.g., Lynch et al. 2009; Bennett and Hatfield 2013), whereas in others it can be detrimental (e.g., Brazel et al. 2004) or mixed (Nöteberg and Hunton 2005).

\section{Defensive Bolstering}

Along with the aforementioned communication theories, differences could arise in responses to different communication media based on varying levels of ability to engage in defensive bolstering. When an individual is committed to a particular position, and is accountable to another party, the individual is likely to engage in a process known as bolstering (Tetlock et al. 1989). This is relevant to an audit context because a client is accountable to an auditor, and is also likely committed to their own pre-existing accounting positions. The client typically is aware that the auditor is seeking a more conservative position (i.e., typically income-reducing), while the client typically seeks to report higher income. As a result, the client may engage in bolstering, and can do so by biasing their responses towards information that supports their position (cf. Chaiken et al. 1996). 
Prior research has shown that defensive bolstering is a cognitively taxing process that requires greater cognitive resources (Eagley 2007). This is because it requires effort to consider the impact of each item an individual conveys to the other party in order to ensure that the item does not damage the individual's pre-existing position. In contrast, it is a relatively easy process to provide information without evaluation or to simply provide information that is consistent with the other party's views (Tetlock et al. 1989). In the context of different communication modes, defensive bolstering should decrease in response to a phone or F2F request as compared to an e-mail request due to the presence of additional "cues." For example, both phone and F2F include vocal inflection (e.g., tone of voice), while F2F also includes visual cues (e.g., nonverbal gestures, appearance, etc.) (Suh 1999). In comparison, an e-mail request includes only words. The additional cues in phone and F2F may increase cognitive load (cf. Ferran and Watts 2008; Sussman and Siegal 2003), reducing the ability to engage in defensive bolstering.

Several studies demonstrate a reduction of defensive bolstering when cognitive resources are depleted. Fischer et al. (2007) conducted several experiments to investigate the effects of resource depletion on self-evaluations. They found that individuals with depleted resources present a less-optimistic self appraisal and are more pessimistic about their future. Particularly relevant for the current study, depleted individuals provided less positive descriptions of their personal attributes, demonstrating a reduction of bolstering participants’ self-image. In a similar study, Fischer and his colleagues found that distracting participants during decision making leads to more balanced information processing (Fischer et al. 2010). Fischer et al. (2010) posit that this occurs because 
distraction leads participants to exhibit less confidence in their judgments and to hold their decision preference less strongly, decreasing confirmatory biases.

Along the same lines, Jonas et al. (2005) investigated whether individuals who provide information as an advisor rather than for themselves will engage in defensive bolstering. They found that when an individual is an advisor for someone else's decision, they engaged in a more balanced information search than individuals who make a decision for themselves. However, if the individuals as advisors were asked to make a decision for their clients, they "revealed an increased preference for information supporting their position.” While Jonas et al. (2005) did not test the effects of distraction/cognitive load in this study, they did demonstrate that even a third party will engage in defensive bolstering if they are adequately involved in the ultimate decision.

Together, these studies on defensive bolstering, along with social presence theory in the communication mode literature, suggest that audit requests via e-mail vs. F2F and phone will lead to differential responses from clients.

\section{Professional Tone}

Cheney and Ashcraft (2007) provide a review of the literature on professionalism in communication studies. They note that there are many aspects to professionalism and that professionalism is setting-dependent. Generally, they state that in a business setting, professionalism generally involves subjugating individuals to dominant norms, and suppressing "spontaneity, emotionality, and individuality" (p. 162). Much of the research in this area is survey based, although some experiments have been conducted. 
Many accounting professionals view appropriate professional communication to include proper writing. Jones (2011) surveyed accounting managers regarding the importance of certain communication skills, as well as their satisfaction with new staff auditors' performance in each of these areas. The following writing and communication skills were the three highest ranked in importance: “Organizes information into effective sentences and paragraphs,” "Writes clearly and precisely,” and "Produces correctly spelled documents.” However, the first two were among the three items (out of over 25 items) where the managers were the least satisfied. This indicates that proper writing is perceived as a problematic area by accounting managers. Compounding this problem, additional surveys show senior firm personnel believe that younger professionals overestimate their communication skills (Ernst \& Young 2008). Jackson (2012), in a survey of business undergraduates, confirms that new professionals are overconfident in their abilities when compared to prior assessments by experienced professionals.

Carr and Stefaniak (2012) conducted an experiment investigating the kinds of judgments a recipient of a less professionally worded e-mail will make about the sender. Student participants reviewed a fictional recruiting e-mail from an HR Director at an accounting firm to the class instructor. The e-mail was either properly written or contained extensive spelling, grammar, and punctuation errors. When the e-mail was written poorly, the participants generally viewed the sender as less credible and competent, and having less organizational prestige. However, this effect was mitigated simply by adding "Sent from my iPhone" to the bottom of the message, indicating that if the participants saw this they were more forgiving of errors since it is harder to correct errors on an iPhone. 
Another aspect of professionalism is politeness and formality. Waner (1995) and Jones (2011) both found that professionals believe it is important to use a proper tone and formality in professional communications. Jessmer and Anderson (2001) conducted a within-subjects experiment asking undergraduates to assess characteristics of the sender based on whether the communication was polite or impolite, and whether the message contained proper or improper grammar. Proper grammar and politeness both led participants to view the sender as more competent. Additionally, participants were more likely to want to work with a sender who was either more polite or who had better grammar in their communication.

However, while all these studies investigated perceptions regarding certain aspects of professionalism (proper tone, politeness, writing skills), no study to my knowledge has investigated whether a less professional communication can lead to changes in performance outcomes, a gap in the literature that this dissertation addresses.

\section{$\underline{\text { Norm Violations }}$}

Because professionalism involves adherence to certain norms of behavior and communication (Cheney and Ashcraft 2007), it is possible that experienced professionals may view a less professional communication as norm violating. The literature on norm violations suggests that this can lead to an aversive reaction. This may be in the form of less cooperativeness (Cialdini and Goldstein 2004) or disapproval and attempts to reprimand or control the norm violating behavior (Brauer and Chekroun 2005).

Much of the research in this area involves evaluations of the norm-violating communicator, rather than investigating behavior towards the communicator (see Levine 
et al. 2000 for a review). However, several studies investigate the manner in which receivers of a norm-violating communication or behavior react to the individual committing the norm violation.

Brauer and Chekroun (2005) investigated whether an individual will express disapproval to a violator of social norms. In a series of field studies, they tested whether bystanders would comment on a confederate’s norm violating action. These violations included posting an advertisement over a bus schedule, cutting in line, littering, and drawing graffiti. They found that people were more likely to engage in expressions of social control if the norm violating behavior was more personally relevant (e.g., cutting in line and littering in an apartment complex entrance hall, vs. placing a poster over a bus schedule or littering in a park). Expressions of social control included expressing anger, disgust, or disapproval, with techniques ranging from facial expressions and audible sighs to direct comments.

Fehr and Fischbacher (2004) confirm that there is inadequate research on responses to norm violations. They discuss research using experimental games to observe reactions to non-normative behavior, noting that those who punish non-normative behavior often do so by becoming less cooperative with the norm-violator. The psychology and communication literature also states that individuals will evaluate normviolating communicators more carefully, suggesting a more systematic process. Burgoon and her colleagues developed expectancy violation theory (EVT) to model reactions to departures from norms or otherwise expected behavior. ${ }^{6}$ One of the propositions of EVT

\footnotetext{
${ }^{6}$ In the communications literature, debate exists on whether norm violations and expectancy violations represent separate constructs (see Levine et al. 2000). However, they are considered highly correlated and include similar predictions. Further, White (2008) notes that EVT includes both "predictive expectancies"
} 
is that negative expectancy violations should lead to negative outcomes (Burgoon et al. 1995). In the accounting literature, Clor-Proell (2009) investigated the effects of an expectancy violation on investors' views of management's credibility, as well as the effect on their investment decisions and information search efforts. Clor-Proell noted that expectation violations theory (EVT) predicts more systematic processing of an unexpected communication, due to a need to more closely evaluate the source of the expectancy violation. She expected that this would predict increased information search on the part of investors. This was found in her second experiment; in her first experiment, she found a marginal increase in the amount of time spent on the task, suggesting greater levels of effort in response to an expectancy violation.

In general, though, this literature suggests the possibility that individuals may react less cooperatively to a norm violating request. Additionally, in the absence of additional cues (see the earlier section on communication mode), the wording in e-mail may be more salient (Suh 1999). Accordingly, it is possible that there may be a greater reaction to a norm violation in e-mail vs. other modes of communication.

\section{Client Agreement with Auditor Adjustments}

Prior research in auditing shows that auditors and clients often engage in negotiations over accounting issues, particularly issues that involve estimation uncertainty (e.g., Gibbins et al. 2001; Gibbins et al. 2007). While the survey literature has looked often at both sides of the auditor-client negotiation process, most experimental

for behavior we expect to occur and "prescriptive expectancies" for behavior we prefer to occur. The latter can be said to include expectations regarding behavioral norms. 
research has focused on the auditor side of negotiations (Salterio 2012). However, several studies have looked at client reactions to different audit strategies.

After Gibbins, Salterio and their colleagues provided initial survey data on auditor-client negotiations, Bame-Aldred and Kida (2007) provided data on both client and auditor initial positions and strategies on opposite sides of the same negotiation. Amongst their findings, they noted that clients have more flexibility in their negotiation stances and could also be more aggressive in their opening positions. In addition, auditors underestimated the range of adjustments that the clients were willing to accept. In contrast, the clients were much more accurate in predicting the auditors' acceptable ranges of outcomes, likely because $85 \%$ of the clients had audit experience.

Most experimental studies have manipulated a fictional negotiation counterpart in order to test a specific causual proposition. ${ }^{7}$ Sanchez et al. (2007) investigated whether clients would react favorably to an auditor's reciprocity-based strategy. If an auditor waived small immaterial adjustments and revealed this fact to the client, the client was more likely to concede a material adjustment in a negotiation with the auditor than if the waived adjustments were not revealed. Sanchez et al. posited that this was because the clients were engaging in the norm of reciprocity, in which they felt obligated to provide something to the auditors since the auditors had provided a concession to the client, regardless of the fact that the initial concession was immaterial.

Tan and Trotman (2010) investigated the effects on the client of the auditor's timing of concessions. They had four conditions manipulating the timing of the auditor's

\footnotetext{
${ }^{7}$ Wang and Tuttle (2009) used an experimental economics setting to test an interactive negotiation setting between "clients" and "auditors." In this study, they investigated the effect of mandatory auditor rotation regimes on auditor-client negotiation strategies.
} 
concessions: either entirely in the first round (of four rounds), entirely in the second round, entirely in the final round, or gradually over each of the four rounds. Clients agreed to larger income decreasing adjustments when the auditor concessions were offered gradually over the four rounds or completely in the final round, and they were also more satisfied with the negotiation outcome and were more likely to want to continue the relationship with the auditor. Together, these results suggest that auditors should not concede quickly.

Perreault and Kida (2011) investigated four persuasion tactics and two communication styles. The persuasion tactics were threaten to qualify the opinion, threaten with a quality review, refer to the opinion of the technical office, or note that other companies use the same method (social reference). Social reference was the most persuasive tactic, along with threatening to qualify. However, threatening to qualify reduced positive affect towards the auditor, as well as client intention to continue with the auditor. Therefore, it appears that social reference was most effective. Further, they investigated a cooperative vs. contentious approach. The cooperative approach was both more effective and engendered more positive affect.

Finally, Perreault, Kida, and Piercey (2013) look at whether clients will concede more if issues are negotiated either simultaneously or sequentially. They find that negotiating multiple issues simultaneously leads to greater client concessions, as does presenting larger issues first.

While these studies primarily look at the effects of various auditor negotiation strategies on client concessions in an auditor-client negotiation setting, none of these consider the effects of earlier client behavior on their later negotiation behavior. In the 
current study, I specifically investigate whether clients are more or less likely to accept an auditor's income-reducing proposed adjustment if the client had previously revealed an information set that is more biased towards items that support the client's position.

\section{Fluency Effects}

Psychological research into fluency effects suggests that a client would be more willing to accept an argument if they had previously revealed the information themselves. Garcia-Marques and Mackie (2001) conducted an experiment to demonstrate that arguments are more persuasive after repeat exposure. In their experiment, 120 undergraduate students were either exposed to 0,1 , 2, or 4 repetitions of information. Additionally, Garcia-Marques and Mackie manipulated whether the argument was strong or weak. They found that more repetitions resulted in no difference in the acceptance of strong or weak arguments, whereas no repetition led participants to differentiate between strong and weak arguments. This implies that individuals are more likely to accept an argument without criticism based on multiple exposures to the same information. Interestingly, it only took 1 repetition of the information to cause no difference between weak and strong arguments (1, 2, and 4 did not differ).

In a follow-up study, Claypool et al. (2004) looked at whether personal relevance had an effect on acceptance of arguments based on repeat exposure. They found that repeated exposure for issues with higher personal relevance led to greater acceptance of strong arguments vs. no repetition, as well as greater differentiation between strong and weak arguments. 
In the current study, I am positing that having personally revealed information essentially increases exposure to the items the participants choose to reveal (otherwise, all exposure to the items is constant). In the context of my study, the repetition is selfgenerated (i.e., the participants themselves cause the repetition by writing down certain items). Following the results of the aforementioned studies, it would be expected that if the participants personally reveal an information set that is more biased towards items that support their position (therefore, revealing a set of information that suggests less of an obsolescence problem), they are exposed less to the disconfirming items and will likely be less accepting of arguments in support of an income-decreasing adjustment.

\section{Summary}

Audit inquiry is an important and often used methodology for gathering information and investigating unusual or unexpected fluctuations (Trompeter and Wright 2010). The literature on communication mode and professional tone suggests that there could be differences in responses to requests via e-mail vs. F2F or phone, as well as a less professional vs. a more professional communication. Further, the literature on fluency effects suggests that there could be a difference in client acceptance of an auditor's proposed adjustment if the client provides a more biased response to the original request. 


\section{CHAPTER 3}

\section{METHODOLOGY}

To investigate the effects of communication mode and professional tone on client responses to audit inquiries, I conducted an experiment to test the responses of clients to an audit inquiry sent either via an e-mail, a video, or an audio recording. I also manipulated whether the wording of the communication was more or less professional. After they responded, I then asked clients the extent of their agreement with an adjustment proposed by the auditor. Finally, I asked various post-experimental questions to measure certain attitudes of the participants.

\section{Hypotheses}

\section{Hypothesis 1}

Based on the literature on communication mode discussed in the prior chapter, it would appear that in response to an e-mail request from an auditor as compared to a visual or audio request, a client is more likely to engage in defensive bolstering or to be less cooperative as a result of reduced social presence. Defensive bolstering is a systematic process that requires greater cognitive resources. The presence of additional cues in visual and audio communications (e.g., vocal inflection, non-verbal gestures, and appearance) can cause cognitive depletion, reducing an individual's ability to bolster their position. Therefore, a client may be better able to engage in defensive bolstering in response to an e-mail request. Further, because audio and visual requests involve greater social presence than an e-mail request, clients are more likely to be cooperative and 
provide a less biased set of information to the auditor in response to an audio or visual request. Accordingly, I propose the following hypothesis:

H1: Participants will provide an information set that is more biased towards items that support their position vs. items that do not support their position in response to an e-mail inquiry as compared to an audio or visual inquiry.

It is unclear whether there will be a difference between responses to audio and visual requests. Social presence theory would suggest that an individual would be more cooperative in response to a F2F request than a phone request (Short 1974), although Daft and Lengel (1986) suggest that there may not be a difference for a relatively simple request. Due to the uncertainty whether the task in this study may be considered simple or not, I make no prediction whether responses to audio or visual inquiries will differ.

\section{Hypothesis 2}

As noted in the literature review, a less professional tone could lead to an aversive reaction to a perceived norm violation. This reaction could be in the form of reduced cooperativeness with the auditor. Accordingly, I would expect that a less professional request should lead to a response that is more biased towards items that support the client's position, leading to the following hypothesis:

H2: $\quad$ Participants will provide an information set that is more biased towards items that support their position vs. items that do not support their position in response to an inquiry with a less professional tone as compared to a more professional tone. 
Also, it is possible that the professional tone is more salient in an e-mail, due to the absence of additional cues. If that is the case, this would suggest that reaction to the norm violation would be exacerbated in the e-mail condition and attenuated in the audio and visual conditions. While theory would suggest this tendency, the extent of the exacerbation and attenuation is unclear. I explore this possibility in the results section in the next chapter.

\section{$\underline{\text { Hypothesis } 3}$}

Finally, based on the literature on fluency effects discussed in the prior chapter, I predict that clients are less likely to agree with a proposed income decreasing adjustment if they previously provided a response that is more biased towards items that support their position. This leads to my final hypothesis:

H3: If a client provides a response set that is more biased towards items that support the client's position, the client is less likely to agree with an auditor's subsequent proposed income-reducing adjustment.

\section{$\underline{\text { Participants }}$}

Participants were 183 experienced business professionals enrolled in management training programs. They had an average of 11.6 years of business experience and 6.0 years of managerial experience. The mean age of the participants was 37 and 32\% were female. Results did not vary by gender and age is not a significant covariate.

It is generally recommended that auditors inquire with both financial and nonfinancial personnel within an organization (Messier et al. 2012). Participants' professional roles included upper level executives (e.g., CFOs, controllers, and vice- 
presidents), operations managers, financial analysts, and sales managers. ${ }^{8}$ In the results section, I analyze whether results are affected by managerial experience, executive vs. non-executive role, and financial vs. non-financial personnel.

\section{Manipulations}

The experiment was administered online via Qualtrics. Participants engaged in a task in which an auditor requests information related to inventory obsolescence. There were two manipulated independent variables: communication mode (e-mail, audio, or visual) and professional tone of the communication (more professional vs. less professional), resulting in a 3x2 between-subjects design. The flow of the experiment can be seen in Figure 3.1.

Participants were told either that the junior auditor "sent you an e-mail. Please click the button to read," "calls you on the phone, please click the button to listen," or “comes to see you in person. Please click the button to see.” Dependent on condition, participants read an e-mail, listened to an audio track, or saw a video. The visual condition showed a video of the same auditor from the introduction video. He makes the same request as the e-mail condition, using the same wording. The audio condition was the audio track from the video.

The additional manipulation was whether the wording was more or less professional. The wording of the less professional tone was developed based on a

\footnotetext{
${ }^{8} 16 \%$ of the participants were upper level executives, $63 \%$ were management level, and $21 \%$ were experienced business professionals without management experience.
} 
STAGE 1: INQUIRY

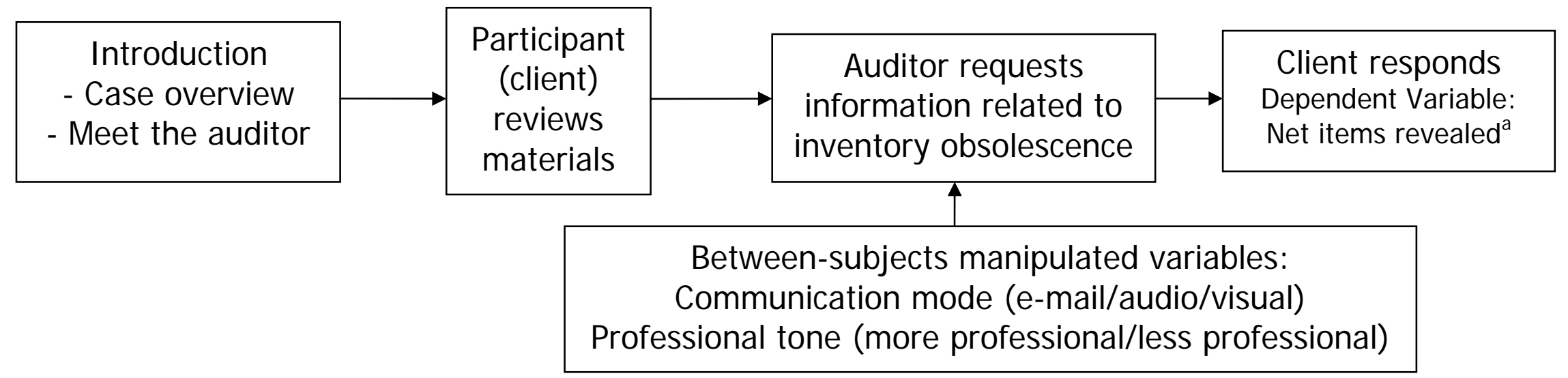

STAGE 2: PROPOSED AUDIT ADJ USTMENT

\begin{tabular}{|c|c|c|}
\hline Audit partner & \multirow{4}{*}{$\begin{array}{l}\text { Client responds } \\
\text { Dependent Variables: } \\
\text { - Agreement level } \\
\text { - Accept (Yes/No) } \\
\text { - Counterproposal } \\
\text { - Maximum acceptable }\end{array}$} & \multirow{4}{*}{$\begin{array}{c}\text { Post-experimental } \\
\text { questions }\end{array}$} \\
\hline decreasing & & \\
\hline $\begin{array}{l}\text { adjustment for } \\
\text { inventory }\end{array}$ & & \\
\hline obsolescence & & \\
\hline
\end{tabular}

\footnotetext{
${ }^{\text {a }}$ Net items revealed $=$ The number of items revealed by the client that support a write-down for inventory obsolescence less the number of items revealed that do not support a write-down for inventory obsolescence. Lower values represent a client response that is more biased towards items that support the client's position of no inventory obsolescence.
} 
preliminary study in which senior auditing students were provided with the front end of the experimental instrument and were asked to compose an inquiry to the client regarding inventory obsolescence. Examples from students who had one to five months of audit experience, most with Big 4 firms, were considered. The wording of the less professional condition was also provided to several corporate managers and an audit partner, who each provided feedback on the realism as well as their experience with e-mails from inexperienced professionals. Some changes were made based on this feedback.

The specific wording of each professional tone condition can be seen in Table 3.1. In order to prevent potential confounds between the spoken and written conditions, the email does not include grammar errors or misspellings, even though this is a common problem in e-communication (cf. Carr and Stefaniak 2012). ${ }^{9}$

\section{$\underline{\text { Experimental Design }}$}

The experimental scenario was adapted from Fanning and Piercey (2013), with financial information adapted from Cohen et al. (2005). Participants assumed the role of a client manager responsible for interfacing with the auditor concerning inventory questions. The background material stated that "like most companies, it is the goal of management to present income as high as possible. However, the company does not want to receive a qualified audit opinion, which would indicate that the auditor believes the

\footnotetext{
${ }^{9}$ In my preliminary study of senior auditing students, these problems were common, even among students with experience in Big 4 and other large accounting firms.
} 
Table 3.1 - Wording of Professional Tone Manipulation

\section{More professional wording:}

“As previously discussed, I am working on the audit of inventory and I have several questions for you.

We have concerns about a potential inventory obsolescence issue related to your product. If there were an obsolescence problem, it could indicate the need for a write-down of the inventory value to the proper market value which, of course, would reduce your net income.

To aid in our analysis, could you please provide me with information regarding any new products from other companies that are superior to your product? Please describe how this could affect sales of your product and whether you would have to sell your product at a loss.

If you believe there are factors that mitigate a potential obsolescence problem, please let me know.

Thank you, I appreciate your time.”

\section{Less professional wording:}

“As I said before, I’m doing the inventory audit and I’ve got some questions.

We think there might be a problem with the inventory numbers. I mean there may be an inventory obsolescence problem. And if that happens we might need to write down the numbers for inventory to be at the real market value which is going to reduce your net income.

So we can look at this and figure out if there's a problem, let me know are there any new products from other companies which are better than your product? We are wondering what could this do to your product sales and could it make it that you'd have to sell your product at a loss.

If you think there are things that make you believe there's not really an obsolescence problem, let me know.

Thanks." 
financial statements are materially misstated." ${ }^{10}$

Participants were first introduced to the junior staff auditor. In a video, the auditor introduces himself as "Ryan Miller” and says that he is working on the audit of inventory. The purpose of this introductory video was to hold constant exposure to the auditor's image and voice, ruling out that any effects found arise from the fact that participants inthe e-mail condition have not seen or heard the auditor, and participants in the audio condition have not seen the auditor.

The participants were then given an opportunity to review information about the company and the company’s products. They were also informed that they would be allowed to refer back to the materials if needed. The information included company background, selected financial information including inventory performance measures, and eighteen specific information items about the company’s products and related obsolescence risks. Half of these items supported a write-down of inventory obsolescence and, therefore, did not support the client's position that no write-down is necessary, while half of the items did not support a write-down of inventory, supporting the client's position of no inventory obsolescence. Examples of items that supported an inventory obsolescence write-down include: “One of the division’s VPs discovered at a trade show that the competition has designed a technologically superior product that has the potential to make ManuTech’s component technologically obsolete”; "Some customers have already pre-ordered the new device from the competition"; and "The price point at which

\footnotetext{
${ }^{10}$ This statement, adapted from Perreault et al. (2013), was designed to provide the client position to the participants and to induce enough of an incentive so that participants would not simply agree with everything the auditor proposed. It is interesting to note that $42 \%$ of the participants engaged in persuasion attempts, i.e., rather than just provide information, they actively attempted to convince the auditor there was no obsolescence issue. This was despite having no incentive to do so, other than this statement. Only $6 \%$ indicated in their response that they thought the inventory was obsolete (the remaining 52\% did not provide an opinion in their response).
} 
ManuTech's component could be sold in international markets would probably not be enough to cover the product costs for the component.” Items that did not support an inventory obsolescence write-down include: "It is an open question as to whether or not the competition will be successful at taking away ManuTech's market share as the Company’s products have an established reputation in the market"; "It might be possible that ManuTech’s existing component could continue to serve existing customers’ needs until the commercial success and cost competitiveness of the competitor's new technology is established"; and "Some sources suggest that the competition may not have done adequate testing of their new product.” A full list of the items included can be seen in Table 3.2.

The participants then received an inquiry regarding inventory obsolescence. In the inquiry, the auditor notes concerns about an inventory obsolescence problem and asks about the effects of potential competing products and whether there are mitigating factors that would reduce obsolescence risk. The inquiry is where I implemented a betweensubjects manipulation of communication mode and professional tone.

With e-mail inquiry, individuals have the ability to re-read the text. To control for this between conditions, participants had the option to replay the audio and visual requests. This was possible even while composing their response. This is akin to asking someone to repeat their request and is consistent with the ability to re-read the e-mail.

The participants were then instructed, "In the space below, please compose your response to the auditor.” Participants were able to refer back to the company background, financial information, and inventory-related issues. Their response was automatically 
Table 3.2 - Inventory Related Items in Experiment ${ }^{\mathrm{a}}$

Supports client's position of no inventory obsolescence

- The current year inventory for this component compared to last year's and two years' ago audited figures suggests that the account has not fluctuated very much.

- It is an open question as to whether or not the competition will be successful at taking away ManuTech's market share as the Company's products have an established reputation in the market.

- The Inventory Turnover ratio for this year is similar to what it was last year and two years ago, and it's also similar to the industry average.

- Initial market research suggests there may be a viable third-world international market for ManuTech’s component.

- The Days Inventory ratio for this year is similar to what it was last year and two years ago, and it's also similar to the industry average.

- ManuTech has an international marketing team that aggressively markets older technology products in developing nations around the world through existing marketing and distribution channels.

- Some sources suggest that the competition may not have done adequate testing of their new product.

- ManuTech may be able to repurpose a portion of the technology in the component to sell in other products.

- It might be possible that ManuTech's existing component could continue to serve existing customers' needs until the commercial success and cost competitiveness of the competitor's new technology is established.

Does not support client's position of no inventory obsolescence (supports a write-down of inventory)

- One of the division's VPs discovered at a trade show that the competition has designed a technologically superior product that has the potential to make ManuTech's component technologically obsolete.

- The competition is expected to have their product ready for the market very soon.

- Some customers have already pre-ordered the new device from the competition. 
- The competition's new component will sell at approximately the same price point that ManuTech's component is currently selling.

- The competitor has started taking pre-orders of their component in an attempt to gain market share.

- Significant pricing changes for Manutech’s component may be necessary, in which case profitability will be uncertain.

- The price point at which ManuTech's component could be sold in international markets would probably not be enough to cover the product costs for the component.

- The size of the international market is debatable, so it may take up to four years to sell off the entire inventory of ManuTech's component in those markets, and whether conditions will remain stable in those markets for the duration of the four years is uncertain.

- Repurposing a portion of ManuTech’s existing technology for use in other items would require an up-front investment in retooling the production process. Since profitability is uncertain, the Board of Directors may be resistant to an additional investment in the existing technology.

${ }^{\text {a }}$ See research instrument in the Appendix for order presented.

saved as they worked to prevent loss of text while going back to see and/or hear the request again.

After submitting their response, the participants learned that the audit partner contacted the management team to propose an \$18 million adjustment for inventory obsolescence, or $6 \%$ of the inventory balance ( $17 \%$ of net income). ${ }^{11}$ The narrative states that the proposed adjustment was based on facts provided by the participant, by other

\footnotetext{
${ }^{11}$ Various professionals who pilot-tested or reviewed the instrument, including experienced auditors and corporate managers, provided feedback that this adjustment was perceived as material.
} 
managers, and as a result of other audit procedures. The narrative also included the auditors' description of factors that led to the adjustment. The purpose of this was to ensure that the participants were aware of the reasons for the adjustment, regardless of whether they revealed the information themselves.

Participants were then asked to provide the degree to which they agreed with the proposed adjustment on a ten point scale anchored from strongly disagree to strongly agree. They were then told that the management team wanted their input on how to respond. Specifically, they were asked whether the company should accept the adjustment outright and, if not, how much the company should counter-propose and the maximum write-down the company should be willing to accept.

Finally, the participants were asked various post-experimental questions regarding their opinions of the auditor and audit team. I also asked several questions regarding views on professional technology use and professionalism and then collected demographic data.

\section{Dependent Variables}

\section{Net Items Revealed}

The primary dependent variable was the number of items revealed that support a write-down of inventory minus the number of items revealed that do not support a writedown of inventory, referred to as "net items revealed.” A lower value of net items revealed represents a response that is more biased towards items that support the client's position of no inventory obsolescence. 
Responses were coded by two independent coders and by the author, all blind to experimental condition. The coders had between three and thirteen years of audit experience. The responses were provided to each coder in a different random order. For each response, the coders identified which of the 18 items in the inventory-related issues list were revealed by the participant. ${ }^{12}$ If the participant revealed at least part of a particular item, even if inaccurately, it was considered revealed to the auditor under the logic that the auditor could ask follow-up clarifying questions or search for corroborating evidence. Inter-rater reliability (IRR) was measured using Krippendorff's alpha (Hayes and Krippendorff 2007), which is designed to measure IRR for interval data. ${ }^{13}$ IRR for net items revealed was .808, which indicates a high level of reliability (Neuendorf 2002).

All remaining coding differences were resolved between the three coders without dispute.

\section{$\underline{\text { Measures of Agreement with Proposed Audit Adjustment }}$}

As noted earlier, the participants were informed that the auditor had proposed a material income-decreasing adjustment and the participants were asked questions regarding their level of agreement. The first question asked, "On the following scale,

\footnotetext{
${ }^{12}$ Few participants revealed anything outside of the eighteen inventory-related issues, even though they had other information about the company background and the company's overall financial performance. Accordingly, coders only recorded whether each of the eighteen inventory-related items were revealed.

${ }^{13}$ Net items revealed represents a net count of specific items revealed (interval coding) rather than a categorization of items (nominal coding). The coders did not make a judgment regarding whether the items revealed supported or did not support a write-down. The valence was pre-determined and the coders only identified if an item was revealed, resulting in a count of specific items revealed. Cohen's kappa, which is commonly used for IRR, is only appropriate for nominal coding (i.e., categorization) and cannot be used for more than two coders at a time. Under Cohen's kappa, if one coder concludes that three supporting items were revealed and another concludes that four were revealed, this would be a complete miss, equivalent to one coder finding three items and one finding zero. Krippendorff's alpha appropriately weights responses that are closer to each other. Accordingly, Krippendorff's alpha is a more precise measure when the outcome is a count of items (interval coding) rather than a categorization of responses (nominal coding). See Neuendorf 2002.
} 
please indicate how strongly you agree or disagree with the auditor's proposal of this inventory write-down.” The scale was a 10-point scale anchored with "Strongly disagree” and "Strongly agree.” They were then asked, "Should ManuTech accept the auditors' proposed inventory write-down?” with a possible response of yes or no. The first question represented strength of agreement whereas the second question represented a dichotomous measure of whether or not the participant accepted the adjustment outright.

If they responded that ManuTech should not accept the adjustment outright, they were then asked two questions to measure their opening negotiation positions. The first asked what amount the participant thought ManuTech should counterpropose and the second asked what should be the maximum acceptable adjustment. In both cases, a sliding scale was provided that allowed the participant to answer in millions between $\$ 0$ and \$18 million.

\section{$\underline{\text { Post-Experimental Questions }}$}

After completing the auditor's adjustment section, participants were then asked several attitude and demographic questions. The purpose of the attitude measures was primarily to determine if there were alternative explanations for the primary results. The first section of questions measured certain affective response to Ryan Miller (the junior auditor) and to the auditors overall. On zero to ten scales anchored with "Not at all" and "Very much," participants were asked to indicate the extent to which the junior auditor or the audit team made them feel angry, annoyed, sad, happy, and frustrated. They were then asked their agreement with several statements to measure whether they found Ryan likable, intelligent, competent and credible; whether they found the auditors competent 
and credible; how important it was for them to respond well to Ryan; how obligated they felt to respond to Ryan thoroughly; whether Ryan's questions affected their opinion about the inventory obsolescence write-down; whether Ryan was disrespectful; and whether they would want to work with Ryan or the audit firm again. Finally, they were asked if they felt that the proposed adjustment was unfair.

They were then asked "How professional did you think Ryan was in his request for information?” This question, which was on a 9-point scale anchored with "Very unprofessional" and "Very professional," was to measure the salience of the professional tone manipulation. The participants were also asked how old they think Ryan was.

In the next section, the participants were asked several questions related to their technology usage, including how often they use text messaging or instant messaging for personal and professional communication, as well as how often they use certain social networking sites. ${ }^{14}$ They were then asked to allocate the percent of time that they use certain communication methods for professional use and what percent of the time they would prefer to receive a request for information via different communication methods.

Next, they were asked if they agreed with the statement, "It is important to be professional in your interactions with colleagues and customers/clients.” They were also asked their level of agreement with a statement "compared to other professionals my age, I am generally on the cutting edge of technology.” Finally, they were asked four questions to measure their views on power distance, adapted from House et al. (2004). Greater levels of power distance indicate that an individual believes there should be greater deference to individuals who are higher in an organization. These measures were

\footnotetext{
${ }^{14}$ Although substantially modified, this was developed based on a technology usage scale from Scott and Timmerman (2005).
} 
included in the post-experimental questions to explore whether power distance may be a potential covariate.

The final section of the instrument asked demographic questions, including years of business and managerial experience, professional title, industry, gender, and age. 


\section{CHAPTER 4}

\section{DATA ANALYSIS}

In this chapter, I first detail the results of the participant responses to the auditor inquiry, including the tests of $\mathrm{H} 1$ and $\mathrm{H} 2$. I then explore the salience of the professional tone manipulation and describe additional analyses and a supplemental study designed to further explore the theory that the effects of a less professional communication are related to a perceived norm violation. Following this, I discuss the responses to the measures of agreement with the auditor's proposed adjustment, testing H3. Finally, I explore the results of the post-experimental questions.

\section{Analysis of Client Responses to Auditor Request}

As previously noted, the primary dependent variable was measured based on the difference of the number of items revealed that support a write-down for inventory obsolescence less the number of items revealed that do not support a write-down, referred to as “net items revealed.” A lower value of net items revealed represents a greater extent of bias towards items that support the client's position of no inventory write-down. Descriptive statistics can be seen in Table 4.1, Panel A. The means are presented graphically in Figure 4.1. Panel B of Table 4.1 details ANOVA results indicating a significant main effect for communication mode $(\mathrm{F}=4.35, p=.014)$. Planned contrasts of e-mail vs. audio and visual, presented in Panel C, show that participants who received an e-mail inquiry provided responses that were more biased towards items that support the 
Table 4.1 - Net Items Revealed by Client in Response to Auditor Inquiry

Panel A: Descriptive statistics - Mean ${ }^{\mathrm{a}}\left(\right.$ standard deviation) ${ }^{\mathrm{b}}$ [n]

Request Tone: $\begin{gathered}\text { More } \\ \text { Professional }\end{gathered} \stackrel{\text { Less }}{\text { Professional }} \quad \underline{\text { Average }}$

Request Mode:

$\begin{array}{cccc} & -0.07 & -0.78 & -0.45 \\ \text { E-Mail } & (2.14) & (1.96) & (2.06) \\ & {[28]} & {[32]} & {[60]} \\ & & & \\ \text { Audio } & 0.63 & 0.38 & 0.52 \\ & (1.56) & (1.82) & (1.67) \\ & {[35]} & {[29]} & {[64]} \\ \text { Visual } & & & \\ & 0.33 & -0.03 & 0.14 \\ & (1.75) & (1.28) & (1.51) \\ & {[27]} & {[32]} & {[59]} \\ \text { Total } & & & \\ & 0.32 & -0.16 & 0.08 \\ & (1.82) & (1.76) & (1.80) \\ & {[90]} & {[93]} & {[183]}\end{array}$

Panel B: ANOVA Results

Main Effects
Communication Mode
Professional Tone
Two-way Interaction
Mode x Tone
Error

$\begin{array}{ccccc}\underline{\mathrm{df}} & \underline{\text { Mean Square }} & & \underline{\text { F-statistic }} & \text { p-value }^{\mathrm{c}} \\ 2 & 13.504 & 4.351 & 0.014 \\ 1 & 8.835 & 2.847 & 0.047 \\ 2 & 0.874 & 0.282 & 0.755 \\ 177 & 3.103 & & \end{array}$




\section{Panel C: Planned Contrasts}

$\underline{\text { t-statistic }}_{\text {p-value }^{\mathrm{d}}}$

Contrast of e-mail vs. audio and visual:

E-mail vs. audio

0.002

E-mail vs. visual

1.782

0.038

Contrast of audio and visual (2-tailed)

1.106

0.270

Contrast of professional tone within each level of communication mode:

E-mail

1.709

0.045

Audio

0.743

0.229

Visual

0.769

0.221

\footnotetext{
${ }^{\mathrm{a}}$ Net items revealed $=$ The number of items revealed by the client that support a write-down for inventory obsolescence less the number of items revealed that do not support a write-down for inventory obsolescence. Lower values represent a client response that is more biased towards items that support the client's position of no inventory obsolescence.

${ }^{\mathrm{b}}$ Levene's test of equality of variance indicates no difference in variances ( $\left.p=.092\right)$.

${ }^{\mathrm{C}}$ For the F-test with one degree of freedom, the $p$-value presented is the 1-tailed equivalent $p$-value for a directional hypothesis. An F statistic with one degree of freedom is equivalent to the squared ANOVA contrast t-statistic and results in the identical p-value. For prior uses of this presentation, see Kachelmeier and Williamson (2010), Piercey (2011), and Elliott et al. (2012).

${ }^{\mathrm{d}}$ Unless otherwise noted, $p$-values are 1-tailed based on directional hypotheses.
}

client's position than those who received an audio inquiry ( $\mathrm{t}=2.93, p=.002,1$-tailed $)$ or a visual inquiry ( $\mathrm{t}=1.78, p=.038$, 1 -tailed), supporting $\mathrm{H} 1$. The audio and visual conditions did not differ in terms of response bias ( $\mathrm{t}=1.11, p=.270$, 2-tailed).

At first glance, the differences in net items revealed may not seem large. However, the grand mean of total items revealed was 4.23 items (2.08 items that support the client's position and 2.15 items that do not support the client's position). Therefore, the various differences represent as much as 33\% of the mean total items revealed. 
Figure 4.1 - Net Items Revealed by Client in Response to Auditor Inquiry

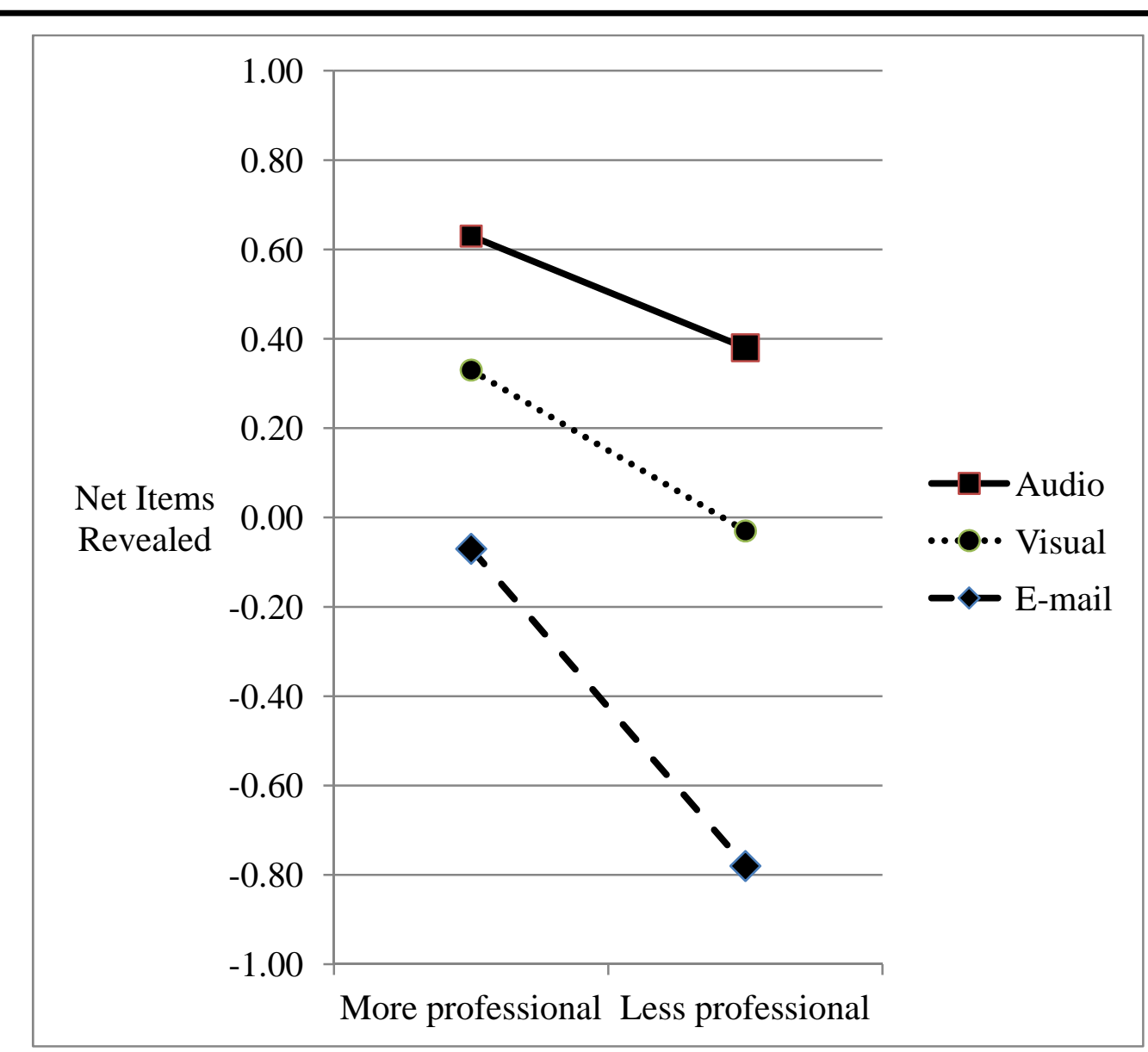

Net items revealed $=$ The number of items revealed by the client that support a write-down for inventory obsolescence less the number of items revealed that do not support a write-down for inventory obsolescence. Lower values represent a client response that is more biased towards items that support the client's position of no inventory obsolescence.

Audio, Visual, and E-mail refer to the communication mode of the auditor's inquiry for information related to inventory obsolescence.

More professional and less professional refer to the professional tone of the auditor's inquiry for information related to inventory obsolescence. The wording of each of these conditions can be seen in Table 3.1.

Calculation of $\omega^{2}$ for the main effect of communication mode suggests an effect size of .035, which is between a small (.01) and medium (.06) effect size (Field 2013). 
The ANOVA also reveals a significant main effect for professional tone, supporting H2. In response to a less professional tone, participants provided an information set that was more biased towards items that support their position of no inventory obsolescence ( $\mathrm{F}=2.85, p=.047,1$-tailed). The pattern of results presented in Table 4.1, and presented graphically in Figure 4.1, suggests that the effects of professional tone may be more pronounced in the e-mail condition. As previously discussed, since the norm violation may be more salient in the e-mail condition in the absence of nonverbal cues and vocal inflection, the effects of the norm violation could be exacerbated in the e-mail condition and attenuated in the audio and visual conditions. Planned contrasts of professional tone within each level of mode suggest that the difference between responses to inquiries in a more or less professional tone is significant in the e-mail condition ( $\mathrm{t}=1.71, p=.045,1$-tailed $\left.{ }^{15}\right)$, but not in the audio $(\mathrm{t}=0.74, p=.229$, 1-tailed) or visual (t=0.77, $p=.221$, 1 -tailed) conditions. $^{16,17}$

\footnotetext{
${ }^{15}$ While the extent of exacerbation and attenuation was unclear on an a priori basis, the directional prediction for the main effect of professional tone remains consistent across cells, allowing for a one-tailed test.

${ }^{16}$ The interaction term in the ANOVA is not significant $(\mathrm{F}=0.28, p=.755)$. However, Buckless and Ravenscroft (1990) demonstrate that ANOVA is often inadequate for testing an ordinal interaction, primarily because ANOVA attributes most of the sums of squares in an ordinal interaction to the main effects. The interaction term in the standard ANOVA forces orthogonality by assigning contrast weights for a disordinal interaction, which is clearly not in evidence or otherwise predicted. This measurement problem is exacerbated when a factor has more than two levels, as is the case with communication mode (Buckless and Ravenscroft 1990). Accordingly, I conducted a contrast-coded test based on weights for a main effect of communication mode, a main effect of professional tone, and an ordinal interaction of mode and tone in which the effects of professional tone are exacerbated in the e-mail condition. The weights for each cell were $1,-9,3,1,3,1$, where the first two weights are for the more professional and less professional e-mail, then the same respectively for audio and visual. The contrast coded omnibus F-test is significant $(\mathrm{F}=10.39$, $p=.002$ ). This methodology also allows for a test to ensure that the contrast weighting represents a good fit by examining the remaining between-group sums of squares. This test of the residual explained sums of squares is not significant $(\mathrm{F}=0.43, p=.787$ ), suggesting that the pattern of a main effect of communication mode, a main effect of professional tone, and an ordinal interaction of mode and tone is a good fit.
} 


\section{$\underline{\text { Salience of Professional Tone Manipulation }}$}

To provide further support for the theory that the more biased response to the less professional condition was a result of a norm violation, I analyzed participants’ assessments of the professionalism of the request. In the post-experimental questions, participants were asked, "How professional did you think Ryan was in his request for information?” Participants responded using a 9 point scale anchored with 1=Very unprofessional and 9=Very professional. Based on the argument that differences in professional tone are less salient in the audio and visual conditions, leading to less reaction to a norm violation, I expected that there would be less difference in perceptions of professionalism in the audio or visual conditions, whereas perceptions of professionalism should differ in the e-mail condition. Further, the lack of statistical differences in response bias between more and less professional tone in the audio and visual conditions would suggest that assessments of professionalism in these conditions should not differ. Figure 4.2 shows the pattern of means for assessments of professionalism in the primary study. The main effect for professional tone (untabulated)

\footnotetext{
${ }^{17}$ I also analyzed effects of whether the participants were in a financial vs. a non-financial role and an executive vs. non-executive role. Approximately $14 \%$ were in a financial role and approximately $16 \%$ were in an executive role. As a result, analyzing results in an ANOVA with financial vs. non-financial or executive vs. non-executive runs the risk of finding spurious results for the financial or the executive participants since there are so few of each in a cell. However, ANOVAs of just the non-financial participants or just the non-executive participants result in qualitatively similar results for mode and tone as the full sample, although the effect of tone becomes marginal. This is likely a result of a loss of power. Overall, these analyses suggest that the results are not driven by either the participants in a financial role or the participants who are not executives. Further, I conducted a similar analysis excluding participants who had no managerial experience ( $21 \%$ of the sample). Results appear comparable, although the potential ordinal interaction is no longer evident; this is likely again a power issue. There is no a priori reason to suggest that the hypotheses would be different for non-managerial, financial, or executive participants and it would be difficult to obtain more of these particular types of participants. Libby et al. (2002) and Peecher and Solomon (2001) suggest that experiments should not use higher level or more specialized participants if there is no a priori reason to expect that these participants will behave differently.
} 
Figure 4.2 - Client Perceptions of the Professionalism of the Auditor's Inquiry

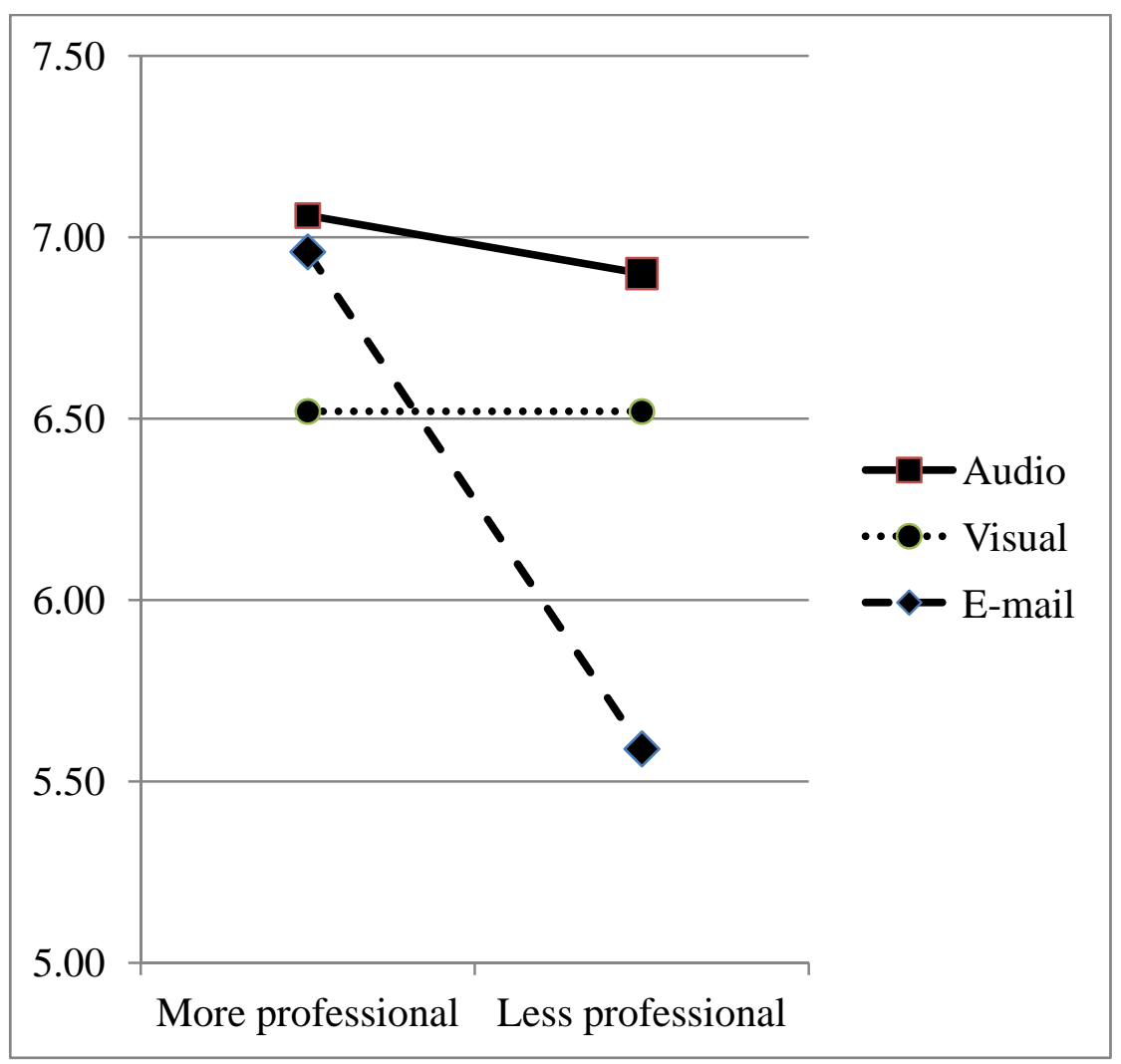

Response to question: "How professional did you think Ryan was in his request for information?" 1=Very unprofessional to 9=Very professional. A lower score means that the participant viewed Ryan's request as less professional.

Audio, Visual, and E-mail refer to the communication mode of the auditor's inquiry for information related to inventory obsolescence.

More professional and less professional refer to the professional tone of the auditor's inquiry for information related to inventory obsolescence. The wording of each of these conditions can be seen in Table 3.1 .

was significant ( $\mathrm{F}=2.07, p=.039$, 1-tailed), indicating that participants in the less professional tone condition viewed the auditor as less professional compared to those in the more professional tone condition. The conventional ANOVA interaction term for mode $\mathrm{x}$ tone was not significant $(\mathrm{F}=2.22, p=.111)$, but the results in Figure 4.2 are highly 
suggestive of an ordinal interaction. Again following Buckless and Ravenscroft (1990), the contrast coded interaction (untabulated) is significant $(\mathrm{F}=10.03, p=.002)$ and the residual is non-significant $(\mathrm{F}=0.42, p=.793)$, indicating that the model is a good fit. ${ }^{18}$

Simple effects of tone within each level of communication mode indicate that only e-mail had a significant difference in perceptions of professionalism, with those in the e-mail/less professional condition judging the auditor's request to be less professional than those in the e-mail/more professional condition ( $\mathrm{t}=2.82, p=.003$, 1-tailed). Assessments of professionalism did not differ within the audio ( $\mathrm{t}=0.48, p=.634$, 2-tailed) or visual ( $\mathrm{t}=0.03, p=.978$, 2-tailed) conditions. The mean perceptions of professionalism for audio and visual did not significantly differ from each other ( $\mathrm{t}=1.30, p=.194$, 2-tailed).

Following recommendations in Hayes (2013), I tested whether there was evidence of moderated mediation via bootstrapping. Specifically, I investigated whether the effects of communication mode and professional tone on net items revealed are mediated by perceptions of professionalism. A bias-corrected bootstrap 95\% confidence interval developed from 10,000 bootstrap samples revealed significant indirect effects of the interaction of mode and tone on net items revealed, mediated through perceptions of professionalism in the predicted direction (the range of 0.001 to 0.525 does not include zero). ${ }^{19}$ Analyzing each level of communication mode and professional tone reveals that the indirect effect only occurred for differences in professional tone in the e-mail

\footnotetext{
${ }^{18}$ In this case, there is no reason to expect a main effect of communication mode as there is no a priori reason to expect that use of e-mail in and of itself is considered less professional. Therefore, weightings of $1,-5,1,1,1,1$ are used where e-mail/less professional is the only cell expected to differ.

${ }^{19}$ For ease of interpretation and analysis, I collapsed the audio and visual conditions as there was no significant difference between the two conditions ( $p=.270$, see Table 4.1, Panel C). As a result, all outcomes reported for bootstrapping are based on a 2x2 between-subjects design, in which mode is varied at e-mail vs. audio/visual and tone is more professional vs. less professional.
} 
condition (indirect effect 95\% confidence interval ranges from -0.507 to -0.014 ) and mode only led to indirect effects on net items revealed when tone was less professional (95\% confidence interval from 0.008 to 0.449$)$. This indicates that differences in net items revealed were mediated by views of professionalism in e-mail, suggesting that the differences in professionalism were only salient in the e-mail condition. ${ }^{20}$

As further support, if differences in reactions to a less professional vs. a more professional tone were in fact a result of aversive reactions to norm violations, then participants with no business experience should have no difference in the bias level of their responses regardless of professional tone. To test this proposition, I collected additional data from 33 senior undergraduate business majors, as well as from 47 additional experienced business professionals. I expected that undergraduates would likely be aware of the need for professionalism, but they lack the skill to perceive differences in professionalism and, accordingly, would not react negatively to the norm violation. $^{21}$

The study had a 2x2 between-subjects design (professional tone (more or less professional) x experienced/inexperienced). The experiment was identical to the main study except I only investigated the e-mail condition and there was no introduction video. The pattern of results can be seen in Figure 4.3. The interaction of professional tone and experience was significant ( $\mathrm{F}=4.55, p=.036$, untabulated). Planned contrasts within each

\footnotetext{
${ }^{20}$ The direct effect of professional tone on net items revealed becomes non-significant when professionalism is included in the model, indicating a mediating effect of perceptions of professionalism.

${ }^{21}$ It could alternatively be argued that the inexperienced participants might not react to the norm violation because they do not view less professional wording as a problem (e.g., their experience with informal writing styles makes them more comfortable with professional norm departures). However, as can be seen in Figure 4.4, these participants failed to even notice a difference in professionalism of the auditor request, implying that the issue was a lack of perception rather than a disregard of an observed norm violation.
} 
Figure 4.3 - Net Items Revealed by Clients in Response to Auditor Inquiry - Study 2

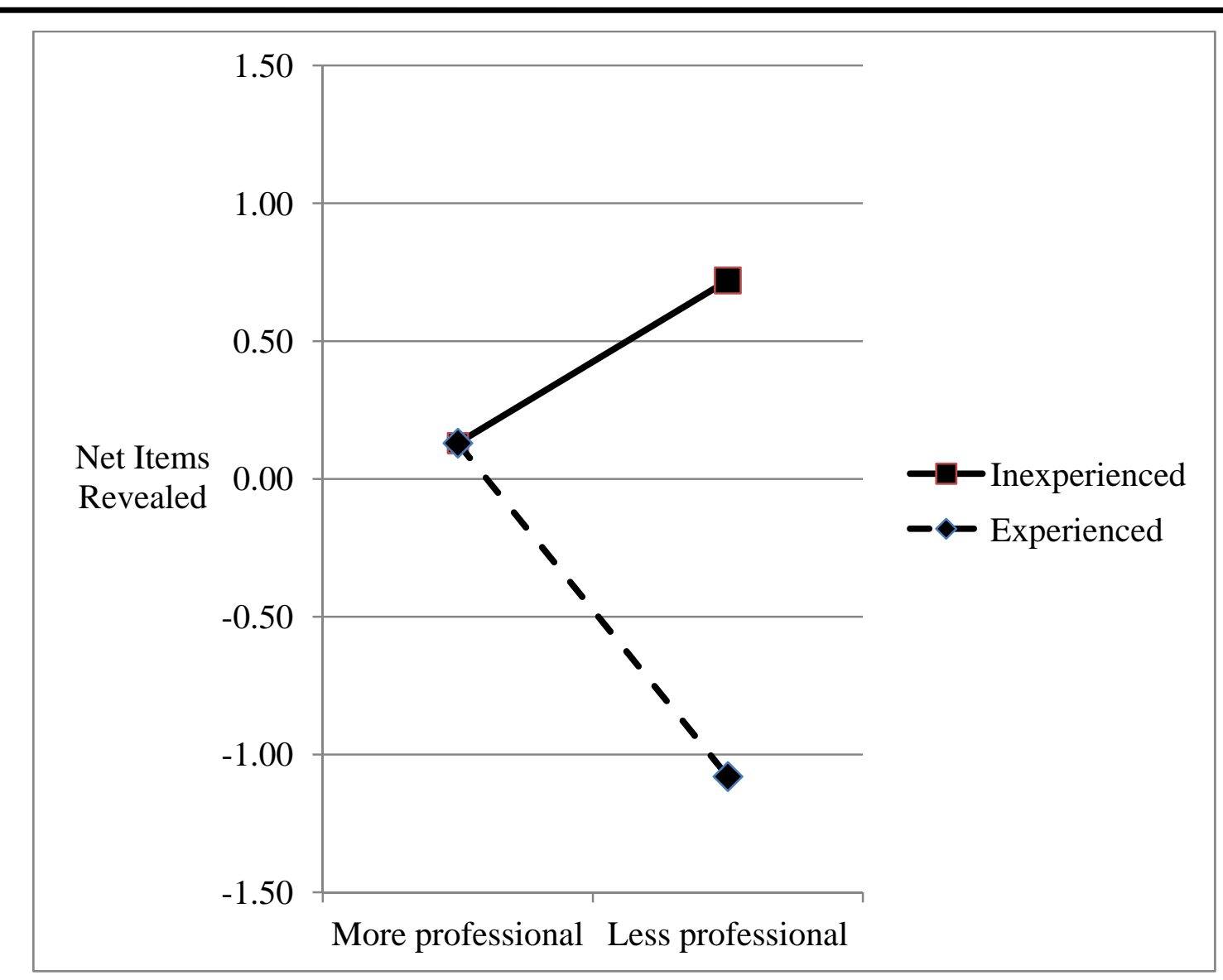

Net items revealed $=$ The number of items revealed by the client that support a write-down for inventory obsolescence less the number of items revealed that do not support a write-down for inventory obsolescence. Lower values represent a client response that is more biased towards items that support the client's position of no inventory obsolescence.

Inexperienced participants were 33 senior undergraduate business students. Experienced participants were 47 experienced business professionals.

More professional and less professional refer to the professional tone of the auditor's inquiry for information related to inventory obsolescence. The wording of each of these conditions can be seen in Table 3.1. In this study, all participants responded to an e-mail inquiry.

level of experience revealed that the inexperienced participants did not differ by professional tone ( $\mathrm{t}=1.06, p=.293$, 2-tailed). Consistent with the main study, the experienced participants differed by professional tone; those who received the less 
professional request provided responses that were more biased towards items that support the client's position of no inventory obsolescence as compared to those receiving a more professional request ( $\mathrm{t}=2.27, p=.013$, 1-tailed), replicating the main study (in this case, without any visual exposure to the auditor) and providing further support for $\mathrm{H} 2$.

To support the argument that inexperienced participants failed to notice the difference in professionalism, I investigated the results of the post-experimental question about professionalism of the auditor's request. The main effect for professional tone (untabulated) was significant ( $\mathrm{F}=2.75, p=.051$, 1-tailed). The ANOVA interaction term was not conventionally significant $(\mathrm{F}=2.08, p=.154)$ although, again, the results shown in Figure 4.4 are suggestive of an ordinal interaction. The contrast coded interaction (untabulated) was significant $(\mathrm{F}=7.95, p=.006) .{ }^{22}$ As can be seen in Figure 4.4, the inexperienced undergraduates had no difference in perceptions of professionalism, regardless of professional tone ( $\mathrm{t}=0.04, p=.968$, 2-tailed), while the experienced business professionals perceived a difference in professionalism, rating the less professional communication as significantly less professional than those in the more professional condition ( $\mathrm{t}=2.44, p=.009$, 1-tailed).

\section{Client Agreement with Proposed Adjustment}

To investigate whether there are downstream effects of failing to elicit information directly from a client, after supplying their response to the audit inquiry participants were told that the auditors proposed an adjustment for inventory obsolescence. They were then asked their level of agreement with the adjustment on a ten

\footnotetext{
${ }^{22}$ As this was a 2x2 between-subjects design, the weights used were $1,1,1,-3$.
} 
Figure 4.4 - Client Perceptions of the Professionalism of the Auditor's Inquiry - Study 2

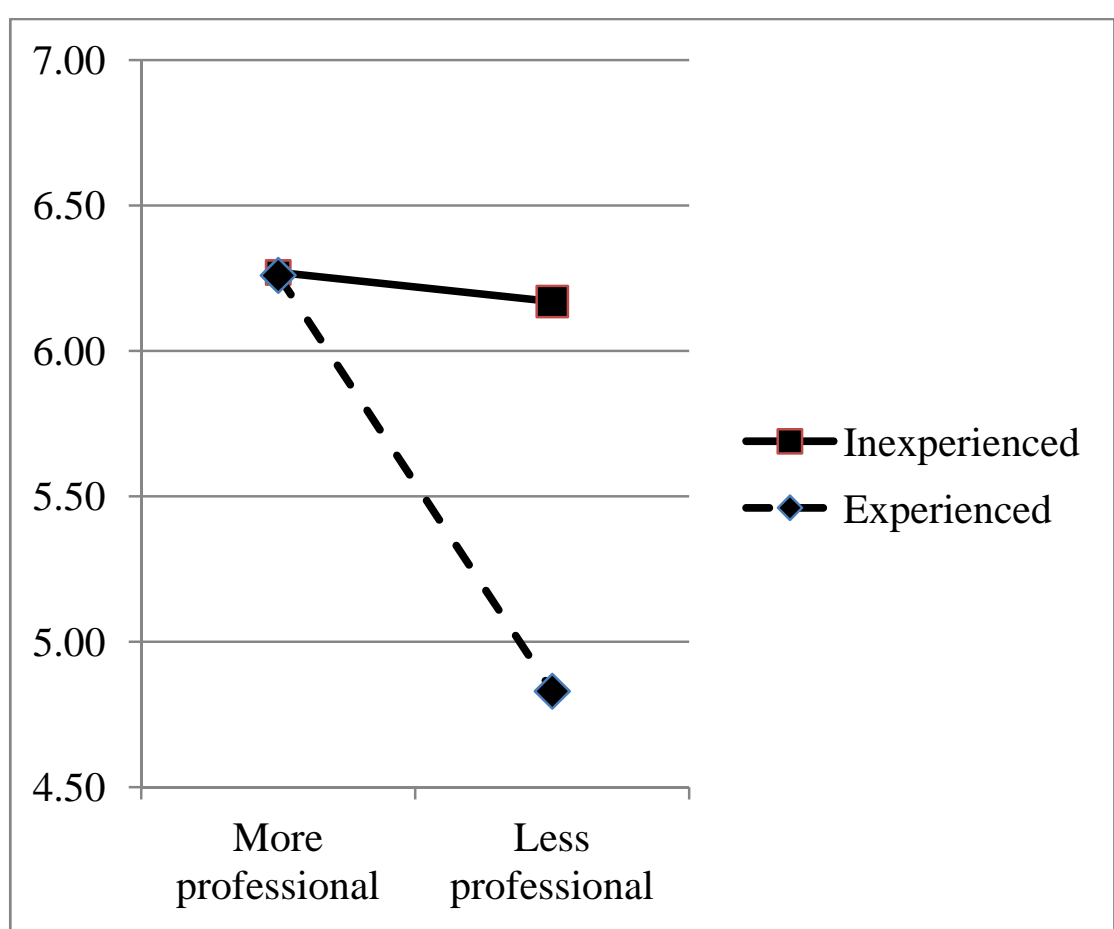

Response to question: “How professional did you think Ryan was in his request for information?” 1=Very unprofessional to 9=Very professional. A lower score means that the participant viewed Ryan's request as less professional.

Inexperienced participants were 33 senior undergraduate business students. Experienced participants were 47 experienced business professionals.

More professional and less professional refer to the professional tone of the auditor's inquiry for information related to inventory obsolescence. The wording of each of these conditions can be seen in Figure 3.1. In this study, all participants responded to an e-mail inquiry.

point scale anchored with strongly disagree and strongly agree. They were also asked whether the company should accept the adjustment and, if not, the amount the company should counteroffer. Finally, they were asked the maximum adjustment the company should accept. 
Table 4.2 details descriptive statistics for each of these four dependent variables and the results of regression analyses for each dependent variable with net items revealed as the independent variable. The regression coefficients indicate that if a client provides a set of information that is more biased towards items that support their position, they are less likely to agree with the auditor's proposed adjustment $(b=0.306, p<.001)^{23}$ and they are less likely to accept the auditor's adjustment outright $(\mathrm{b}=0.246, p=.012) .{ }^{24}$ The effects of the influence of net items revealed on audit outcomes are further demonstrated by an analysis of the participants' initial negotiation positions. As noted earlier, prior research has demonstrated that initial negotiation positions are often predictive of negotiation outcomes (Hatfield et al. 2010; Brown-Liburd and Wright 2011). Therefore, if clients initiate negotiations with a lower counteroffer and a lower maximum acceptable adjustment, this would predict a lower final adjustment, potentially affecting audit outcomes. The results indicate that clients who previously provided a response set that was more biased towards items that support their position provide a lower counterproposal ( $\mathrm{b}=0.587, p=.002)$ and have a lower maximum acceptable adjustment ( $\mathrm{b}=0.478, p=.020$ ). Together, these results provide support for H3.

Since communication mode and professional tone affect the extent of bias in the response, and the extent of bias in the response affects the client's willingness to agree with an auditor's proposed income-decreasing adjustment, it stands to reason that communication mode and professional tone may affect agreement with the auditor

\footnotetext{
${ }^{23}$ All p-values in this section are 1-tailed based on directional predictions.

${ }^{24}$ For a logistic regression, the coefficient can be transformed into an odds ratio. This coefficient implies that for each one unit increase in net items revealed (i.e., a less biased response), the client is 1.3 times more likely to accept the auditor's proposed adjustment.
} 


\begin{tabular}{|c|c|c|c|c|c|}
\hline \multirow[b]{2}{*}{ Dependent variable: } & \multirow[b]{2}{*}{ Mean } & \multirow[b]{2}{*}{ SD } & \multirow[b]{2}{*}{$\mathrm{n}$} & \multicolumn{2}{|c|}{$\begin{array}{c}\text { Regression } \\
\text { coefficients for } \\
\text { independent } \\
\text { variable: } N E T \\
\text { ITEMS } \\
\text { REVEALED }\end{array}$} \\
\hline & & & & $\mathrm{b}$ & $p$-value \\
\hline $\begin{array}{l}\text { AGREEMENT LEVEL } \\
\text { ACCEPT (Mean = \% responding }\end{array}$ & 5.32 & 2.30 & 183 & 0.306 & $<0.001$ \\
\hline "Yes") & $21.5 \%$ & 0.41 & 181 & 0.246 & 0.012 \\
\hline COUNTERPROPOSAL & $\$ 6.35$ million & 4.26 & 142 & 0.587 & 0.002 \\
\hline MAXIMUM & $\$ 9.69$ million & 4.44 & 142 & 0.478 & 0.020 \\
\hline
\end{tabular}

All $p$-values are 1-tailed for directional predictions.

\section{Variable definitions:}

NET ITEMS REVEALED

The number of items revealed by the client that support a write-down for inventory obsolescence less the number of items revealed that do not support a write-down for inventory obsolescence. Lower values represent a client response that is more biased towards items that support the client's position of no inventory obsolescence.

AGREEMENT LEVEL Client's level of agreement with the auditor's proposed incomedecreasing adjustment on a scale from $1=$ Strongly disagree to $10=$ Strongly agree.

ACCEPT

Response to Yes/No question, "Should ManuTech accept the auditors' proposed inventory write-down?" $0=$ No, $1=$ Yes. Regression results are from a logistic regression.

COUNTERPROPOSAL Response to question: "If no [on ACCEPT], what amount should ManuTech counterpropose to the auditor for the inventory write-down?" Scale was provided ranging from $\$ 0$ to $\$ 18$ million, moving in \$1 million intervals.

MAXIMUM

Response to question: "What is the maximum amount of inventory write-down you think ManuTech should be willing to accept?" Scale was provided ranging from $\$ 0$ to $\$ 18$ million, moving in \$1 million intervals. 
indirectly through the extent of bias in the net items revealed. Following procedures recommended by Hayes (2013) for testing indirect effects, I used a bias-corrected bootstrapping analysis based on 10,000 bootstrap samples and generated a 95\% confidence interval for each test of indirect effects. The confidence intervals revealed either significant (the confidence interval does not contain zero) or marginally significant indirect effects of communication mode and professional tone on the various measures of agreement with the auditor through net items revealed. Communication mode indirectly affects agreement with the auditor's proposed adjustment through net items revealed $(95 \%$ confidence interval $=0.053$ to 0.541$) .{ }^{25}$ The indirect effect of professional tone on agreement with the auditor was marginally outside the $95 \%$ confidence interval (-0.381 to $0.001)$.

I conducted similar analyses for each of the other three dependent variables related to agreement with the auditor. In each case, the indirect effect of communication mode on the measure of agreement with the auditor was significant (zero did not appear in the 95\% bootstrap confidence interval). The indirect effect of professional tone on acceptance of the auditor's adjustment was marginally significant, but the indirect effects of professional tone on the counterproposal and the maximum acceptable adjustment were not conventionally significant. Overall, these results indicate that communication mode indirectly affected both the client's propensity to agree with the auditor's proposed income-reducing adjustment and the client's opening negotiation positions through the

\footnotetext{
${ }^{25}$ As in the earlier bootstrapping analyses, for ease of interpretation and analysis, I collapsed the audio and visual conditions as they did not significantly differ.
} 
degree of bias in their response, while professional tone had only a marginal indirect

effect on the client's propensity to agree, but not on their opening negotiation positions. ${ }^{26}$

\section{Supplementary Analyses}

After completing the experiment, I asked several post-experimental questions.

Table 4.3 details the means for each of the post-experimental questions. Except for those specifically noted in the text below, none of these varied by experimental condition. In Panel A, I present the mean responses to the various affect measures. In general, the experiment did not elicit a strong affective response. The affect measures were included primarily because prior research had suggested that affect can be a factor in responses to different types of communication (e.g., Cheshin et al. 2011; Byron 2008). Participants were asked to what extent Ryan Miller (the junior auditor) or the overall audit team separately caused the participants to feel certain types of affect, including anger, sadness, frustration, happiness, and annoyance. The mean responses to affective measures were typically at the lower end of the scale, ranging from 0.66 to 3.57 (on a 0 to 10 point scale anchored with "Not at all” and "Very much"). In the case of sadness and happiness towards Ryan and the auditors, the median was zero, meaning over half the participants felt none of those feelings. The median for anger towards the auditors was 1.00 and the highest median was 3.00 for annoyance and frustration at the auditors. ${ }^{27}$

\footnotetext{
${ }^{26}$ The direct effects of mode and tone on the various measures of agreement with the auditor were not significant, nor were they expected to be, due to the length of the experimental task and due to the fact that communication mode and professional tone were not manipulated with respect to the proposed adjustment. Per Hayes (2013), evidence of a direct effect is not necessary to determine that a significant indirect effect exists.

${ }^{27}$ Pre-testers of the instrument indicated that they were somewhat angry at the auditors for proposing a large income-decreasing adjustment. However, as noted above, it was annoyance and frustration that had the highest median.
} 
TABLE 4.3

Responses to Post-Experimental Questions

Panel A: Mean Responses to Affect Measures ${ }^{\mathrm{a}}$

Item

1. Angry (Ryan made you feel...)

Response

1. Angry (Ryan made you feel...)

1.35

$\begin{array}{ll}\text { 2. Annoyed (Ryan made you feel...) } & 2.71\end{array}$

$\begin{array}{ll}\text { 3. Sad (Ryan made you feel...) } & 1.19\end{array}$

4. Happy (Ryan made you feel...) 0.66

5. Frustrated (Ryan made you feel...) $\quad 2.70$

6. Angry (The auditors (entire team) made you feel...) 2.29

7. Annoyed (The auditors (entire team) made you feel...) 3.49

8. Sad (The auditors (entire team) made you feel...) 1.48

9. Happy (The auditors (entire team) made you feel...) 0.76

10. Frustrated (The auditors (entire team) made you feel...) 3.57

Panel B: Mean Agreement with Statements Regarding the Junior Auditor and Audit Team $^{\text {b }}$

Item

Response $^{\mathrm{c}}$

1. I found Ryan to be likable.

$5.30 *$

2. Ryan is intelligent.

$5.75^{* * *}$

3. Ryan is competent.

$5.90 * * *$

4. Ryan is credible.

$5.84 * * *$

5. The auditors are competent.

$6.13 * * *$

6. The auditors are credible.

$6.11^{* * *}$ 
7. Responding well to Ryan was important to me.

8. I felt obligated to answer Ryan's questions thoroughly.

9. Ryan's questions affected my opinion about the inventory obsolescence write-down.

10. Ryan was disrespectful.

11. I would want to work with Ryan again.

12. I would want to work with this audit firm again.

13. I felt the auditor's proposed reduction of the inventory balance was unfair.

Panel C: Technology Usage

Item

Response

How often do you engage in each of these activities? ${ }^{\mathrm{d}}$

1. Sending and receiving text messages on a cell phone for professional purposes.

2. Sending and receiving text messages on a cell phone to communicate with friends.

3. Using instant messaging (on a computer) for professional purposes.

4. Using instant messaging (on a computer) to communicate with friends.

5. Using Twitter.

6. Using Facebook. 
What percentage of the time do you use each [of the following] method[s] to communicate with others in a professional context?

1. Face to face (in person)

2. Video (e.g. Skype)

3. Phone (land-line or cell phone)

$20.47 \%$

4. E-mail

5. Instant message or text message

$7.92 \%$

What percentage of the time would you prefer to receive a request for information via each of the following communication methods in a professional context? ${ }^{\mathrm{e}}$

1. Face to face (in person)

2. Video (e.g. Skype)

$2.85 \%$

3. Phone (land-line or cell phone)

$17.85 \%$

4. E-mail

$37.09 \%$

5. Instant message or text message

$6.90 \%$

Notes:

a This panel reports responses to several affective measures related to Ryan Miller (the junior auditor) and the overall audit team. The measure asked participants to indicate the extent to which either Ryan or the auditors made them feel a certain affective response. This was measured on a 0 to 10 scale anchored with "Not at all” and "Very much."

b This panel reports the level of agreement with various statements related to the Ryan Miller (the junior auditor) and the overall audit team. The scale was a 9 point scale anchored with "Strongly disagree" and "Strongly Agree.” The mid-point (5) was labeled with "Neither agree nor disagree.”

c For this section, asterisks indicate that the mean response was different from the neutral midpoint: $* * *<.001, * *<.01, *<.05$, all 2-tailed.

d Responses were on a 6 point scale anchored with $0=$ Never and $5=$ Very often.

e Reported amounts are the mean percentage out of 100 . Participants apportioned $100 \%$ to the five different communication modes in each of these cases. 
Panel B presents the participants' level of agreement with various statements related to Ryan and the auditors. The responses were on 9 point scales anchored with Strongly disagree and Strongly agree, with the mid-point (5) marked "Neither agree nor disagree.” Assessments of Ryan’s personal characteristics (likability, intelligence, competence, and credibility) did not significantly vary across conditions, demonstrating that personal opinions regarding Ryan did not drive differences based on mode or tone. Of particular interest, there were no differences across cells in response to the statement "Ryan was disrespectful.” This was important because one of the aspects of professionalism manipulated in the more vs. less professional conditions was the presence of polite courtesies (e.g., saying “please”, see Jessmer and Anderson 2001). This did not lead to differences in perceived respect, which could also affect outcomes.

The experiment also appears to have been successful in motivating participants to view the task as important. In response to the statements "Responding well to Ryan was important to me" and "I felt obligated to answer Ryan’s questions thoroughly," both mean responses were well above the midpoint (mean $=6.97$ and 7.13, respectively). These did not vary across experimental conditions, demonstrating that the differences in net items revealed were not driven by the participants' views of the importance of the task.

Also, in response to the statement "Ryan's questions affected my opinion about the inventory obsolescence write-down,” the mean response only marginally differed from the midpoint marked "neither agree nor disagree" ( $\mathrm{t}=1.65, p=.10,2$-tailed). Interestingly, there was a difference based on professional tone ( $\mathrm{F}=4.52, p=.035)$. Specifically, those in the more professional condition were less likely to agree with this 
statement. Although there was not a significant ANOVA interaction term, the effects appeared to be driven by the e-mail condition. However, the pattern is not consistent with the pattern of net items revealed, suggesting that this is not an explanatory variable. Further, the results for net items revealed do not qualitatively change when including agreement with this statement as a covariate, nor is it a significant covariate.

Regarding willingness to work with Ryan or the audit firm again, both were above the midpoint, although they were slightly more likely to want to work with Ryan again than the audit firm (mean 5.66 vs. 5.32, respectively. Paired-samples t-test: $t=2.58$, $p=.011$, 2-tailed). However, this did not vary across experimental conditions. This was likely a reaction to the proposed adjustment, which is consistent with the mean agreement with the statement, "I felt the auditor's proposed reduction of the inventory balance was unfair," which was above the midpoint (mean=5.64, $\mathrm{t}=3.80, p<.001$ ). There was no difference across cells. I also ran a regression including the response to this statement about the fairness of the adjustment along with net items revealed on agreement with the auditor. The relationship of net items revealed on agreement with the auditor remained significant ( $\mathrm{t}=2.22, p=.028)$ and the assessment of unfairness was highly significant $(\mathrm{t}=-7.14, p<.001)$. This feeling of unfairness, however, could not be a mediator of the indirect effect of communication mode and professional tone on agreement with the auditor, since there is no relationship between mode or tone with perceived unfairness. I asked various questions about technology use. Participants were asked how often they use certain communication methods for professional or personal use on a six point scale anchored with $0=$ Never and $5=$ Very often. They were then asked to allocate the percent of time that they use certain communication modes for professional purposes 
and what percent of time they would prefer to receive a request for information via specific modes of communication (e.g., F2F, e-mail, phone).

The mean responses can be seen in Panel C of Table 4.3. As would be expected based on random assignment, there were generally no differences in tech usage across conditions. $^{28}$ The responses reveal certain characteristics of the participants in this experiment. For example, they are not generally using “cutting edge” communication methods for professional purposes. Instant messaging and text messaging were not often used professionally (means of 1.79 and 2.62, respectively), although they do use text messaging often for personal purposes $($ mean $=4.17)$. They confirm the lack of professional use by saying they use instant messaging or text messaging for professional purposes only $7.92 \%$ of the time on average. In terms of the amount of time that they use F2F for professional communication vs. e-mail (34.95\% vs. 34.62\%, respectively), these were statistically equal (paired samples t-test, $\mathrm{t}=0.14, p=.888$, 2-tailed).

Interestingly, demonstrating that the sample was not made up of people who are resistant to receiving an e-mail request, when asked what percentage of the time they would prefer to receive a request for information via each communication method, e-mail was apportioned the highest percentage (37.09\%), although it was statistically equal to F2F (35.3\%, paired samples t-test, $\mathrm{t}=0.55, p=.584$, 2-tailed).

Finally, I asked several questions related to power distance, to determine if higher power distance scores led to a greater reaction to the norm violation. As would be

\footnotetext{
${ }^{28}$ One exception was there was a main effect of tone on the reported percentage of time that participants claimed to use F2F for professional communication purposes ( $\mathrm{F}=4.15, p=.043)$. When the auditor's request was less professional, participants indicated they use F2F less (approximately 32\% of the time, vs. 38\% of the time for the more professional). This is not a significant covariate when included in the ANOVA of the effects of communication mode and professional tone on net items revealed, nor does its inclusion qualitatively affect the results.
} 
expected based on random assignment, there were no differences across experimental conditions for power distance. I ran an exploratory factor analysis of the four power distance questions. As expected, the questions loaded on two factors, which approximate "how it is [in my organization]" and "how it ought to be" (see House et al. 2004). The former indicates how the participants perceive current conditions in their organization, while the latter measures their personal attitudes towards how much power distance should exist. The first factor (how it is) was not a significant covariate in the ANOVA of communication mode and professional tone on net items revealed. The second factor (how it ought to be) is a marginally significant covariate ( $\mathrm{F}=3.22, p=.074$ ), but it does not qualitatively affect the relationships of communication mode or professional tone with net items revealed.

In summary, none of the post-experimental questions appear to indicate that anything other than assessments of professionalism are driving the professional tone differences. Additionally, none of the post-experimental questions provide alternative explanations for the differences in reactions to the communication mode of the request.

\section{$\underline{\text { Summary }}$}

In summary, my results support my hypotheses that an e-mail request leads to responses that are more biased towards items that support the client's position as compared to audio and visual requests and a less professional tone leads to a more biased response as compared to a more professional tone, and this may be exacerbated in the email condition and/or attenuated in the audio and visual conditions. Study 2 provides evidence that the reaction to the difference in professional tone is due to a perceived 
norm violation, as inexperienced individuals do not notice the difference in professional tone and do not differ in response to a less professionally worded e-mail request vs. a more professionally worded e-mail request, while the more experienced individuals do differ in their responses.

The second phase of the experiment demonstrates the importance of eliciting information directly from the client, as the participants were less likely to agree with the auditor's adjustment if they previously provided a more biased response. Further, they were less likely to accept the adjustment outright and were more likely to negotiate with a lower counteroffer and a lower maximum acceptable adjustment if they previously provided a more biased response. 


\section{CHAPTER 5}

\section{CONCLUSIONS}

The results of this study suggest that there are ramifications to a junior auditor's choice of communication media. Specifically, I find that clients provide responses that are more biased towards items that support their position when responding to an e-mail inquiry vs. an audio or visual inquiry. Further, an inquiry in a less professional tone also leads to a more biased response, and this effect may be exacerbated in the e-mail condition and appears to be the result of a perceived norm violation. In addition, if clients previously provided a more biased response, they are less likely to agree with a proposed audit adjustment and they are likely to negotiate more aggressively in response to a proposed income-decreasing audit adjustment. These findings are particularly important since staff auditors are likely to default to e-mail in order to avoid uncomfortable interactions with senior auditors (Bennett and Hatfield 2013). While Bennett and Hatfield found that junior auditors are more willing to request additional information via e-mail, the current research suggests that this benefit may be attenuated or detrimental overall. In particular, Trompeter and Wright (2010) raise concerns that auditors inadequately search for evidence that disconfirms client responses to auditor inquiries. However, even if the auditors do find the information through alternative audit procedures, increased client resistance to a resulting proposed income-decreasing adjustment could lead towards a less conservative final adjustment.

Accordingly, there are several recommendations that arise from this research. First, audit firms need to be aware of the potential effects of using e-mail for client 
inquiries and firms should alert auditors to these effects. Also, this research underscores the importance of adequate training and attention to professional communication skills, and for educating staff auditors about the potential effects of communicating in a less professional manner. In fact, the CPA Vision Project (2011) lists communication skills as a core competency, referring to the importance of "appropriate delivery and interpersonal skills” (p. 11). The results of this study demonstrate the essential nature of appropriate communication skills.

\section{Limitations and Future Research}

Like all experimental research, this study is subject to several limitations. In particular, I do not look at the effects of interactions between the auditor and the client. The back-and-forth of an actual conversation, whether with high temporal synchronicity as found in a phone or F2F conversation or low temporal synchronicity as found in an email conversation, could potentially have an effect. An alternative experimental approach could have been to use a confederate in the role of the junior auditor who could interact with the participants. However, this would create a challenge regarding extraneous factors that could affect experimental control (e.g., in certain conditions, the confederate could unintentionally provide additional cues to the participants regarding the appropriateness of their responses). The use of a video and audio recording was designed to control for extraneous factors that might have arisen through the use of a confederate, allowing for a cleaner test of direct causative effects of communication mode and professional tone. 
Due to the need to keep the wording constant across communication modes, the current study precluded investigation of the effects of grammar errors or abbreviations commonly used in e-communications, as well as other informalities (cf. Carr and Stefaniak 2012). Future research can look into the effects of these writing styles.

Another limitation of the study is that the clients had no indication of a preexisting relationship with the auditor. It is possible that a pre-existing relationship could mitigate or exacerbate the effects found in this study. For example, the communication model proposed by Swaab et al. (2012) suggests that a positive relationship could reduce differences between e-mail and F2F outcomes. Alternatively, a negative relationship may actually lead to e-mail resulting in a more cooperative response than F2F. However, one of the issues with junior auditors choosing to use e-mail for communications with clients is that they may fail to create a social relationship with clients. Audit partners have indicated during AAA conference panels and in private conversations that junior auditors may not be creating bonds with their clients as a result of defaulting to e-mail use. Many of these partners also indicate that they believe a positive social relationship can lead to a client revealing more information in response to audit inquiries. However, concerns arise regarding whether a stronger social relationship would reduce auditor skepticism towards information and explanations provided by the client. Future research could investigate interacting dyads of auditors and managers to test whether clients reveal more (and/or provide a less biased response) to an auditor after engaging in a social relationshipbuilding task, compared to those who do not develop a social relationship. Further, research can investigate if social relationships affect auditor skepticism with respect to the information provided. 
Another avenue for future research involves the interesting finding that $42 \%$ of the participants in my study attempted to persuade the auditor that there was no inventory obsolescence problem. This was interesting since participants were not asked their opinion on obsolescence, but were only asked to provide information. Client attempts to persuade auditors to their position could have a detrimental effect on auditor skepticism and potentially on audit outcomes. Accordingly, future research could include investigating inquiry techniques that may reduce client persuasion attempts. For example, there may be ways an auditor can ask for information in which the clients focus more on the task of providing information as opposed to focusing on persuading the auditor to agree with a certain position.

Additional research could look at the effects of different incentives on clients' propensity to reveal information. If auditors are aware of clients' incentives (e.g., bonuses or stock options, or fear of job loss), the auditors may consider changing their inquiry approach. Finally, recent research suggests the importance of investigating non-financial information during an audit (Brazel et al. 2009). Future research could look at whether inquiry should differ with respect to financial and non-financial personnel, including investigating ways to improve the non-financial information set provided by clients. 


\section{APPENDIX \\ RESEARCH INSTRUMENT}

The experiment was conducted online using the Qualtrics survey platform. Participants could only go back to previous screens when a "back" button was provided. The following pages have screen shots of each screen in the instrument. For the videos, issues with screen image capture have resulted in the appearance that some images are not centered in the video screen. However, the actual videos were properly centered in Qualtrics. Also, on the following pages some larger screens do not show borders at either the top or the bottom. Again, this is only a function of the screen capture process, and is not indicative of issues in the actual instrument. Titles and descriptions (where necessary) are provided above the screen shots. 


\section{ENTRY SCREEN/INFORMED CONSENT}

Thank you for agreeing to participate in this research study.

In this study, you will take the role of a manager in a company that is currently undergoing its annual financial statement audit. Because of your business background, we are interested in your responses to the scenario presented.

There are no correct answers to any of the tasks or questions asked. We are just interested in your professional judgment. Your participation in this study is completely voluntary. All individual responses will be kept completely anonymous and the results of this research project will be reported only in aggregate form.

If you have any questions or would like further information, please contact the primary researcher: saiewitz@som.umass.edu.

Again, thank you for providing your valuable time!

Click the "Next" button below to signify your consent to participate in the study and to begin. 


\section{CALIBRATION SCREEN}

This screen included a video that showed a test pattern. The picture shows the video in progress.

Before beginning the study, please ensure that your browser is capable of playing video and that your sound is on. To verify this, please press play on the following test pattern video.

You will hear two beeps. You should use these beeps to assist in adjusting your volume prior to beginning the study.

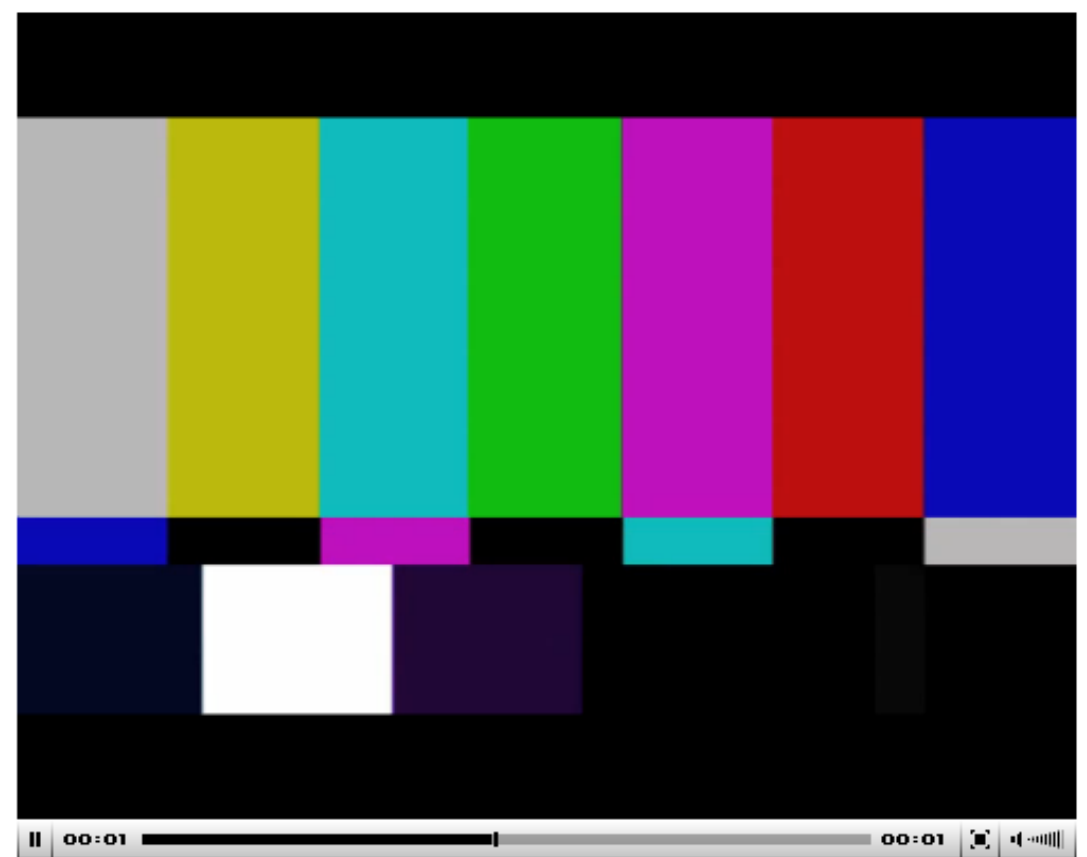

If you cannot see or hear the video, please adjust the settings on your computer and press play again. If you are still experiencing problems, please e-mail the primary researcher by clicking here.

If you can see the video and are satisfied with the volume level, please press the next button. 


\section{INTRODUCTION SCREEN}

In this screen, the auditor says, "My name is Ryan Miller and I'm working on the audit of inventory." The picture shows the video in progress. The actual video is appropriately centered.

\section{Introduction}

In this project, assume that you are a manager in a company that produces high tech hardware. The company is currently undergoing its annual financial statement audit. You will be given background information regarding the company and then will receive inquiries from one of the junior auditors on the audit team. You will be able to refer back to the background materials when you respond to the auditor, but please read the materials thoroughly so that you can respond in a timely manner.

After you respond to the auditor, you will be asked several additional questions related to the case.

The junior auditor, Ryan Miller, recently introduced himself. Please click play on the following video to see.

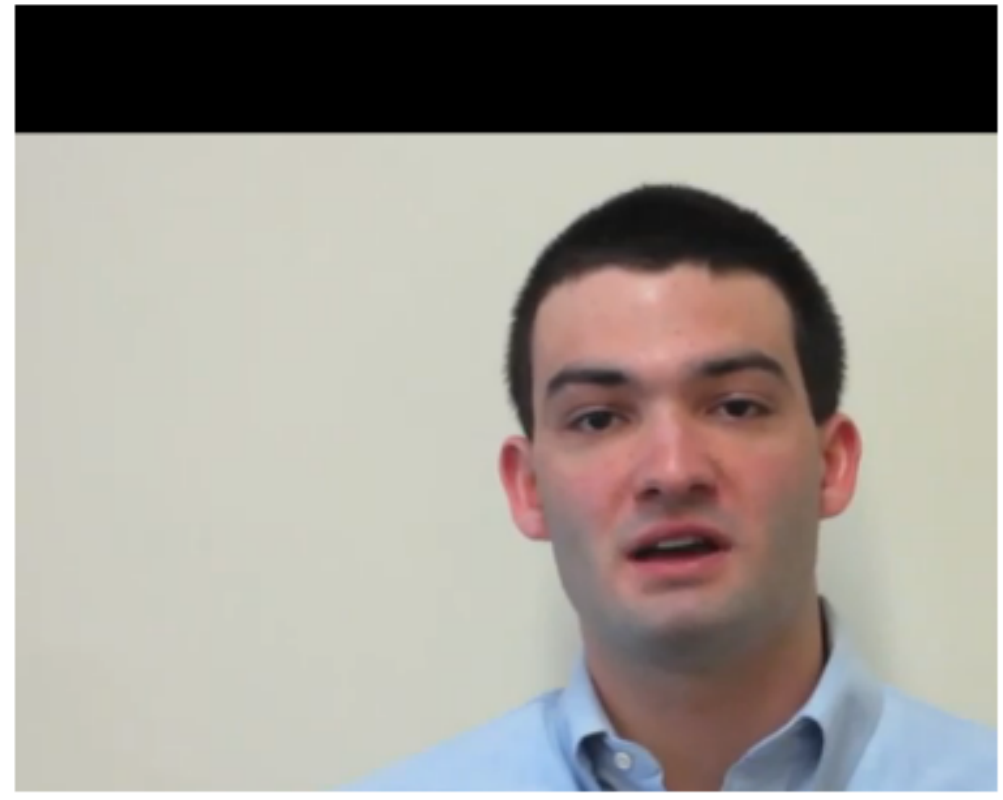

After you have watched the video, please click next. 


\section{SECOND INTRODUCTION SCREEN}

In a moment, you will be provided with detailed information about the division, its operations, and certain issues related to inventory. Please read the information carefully. It is not necessary to memorize the information because you will be able to refer back to it, but it will be easier to respond to the auditor's inquiries in a timely manner if you have thoroughly read and considered the materials. 


\section{Company Background}

ManuTech Incorporated (referred to as "ManuTech" or the "Company") currently designs, manufactures, and sells a range of electronic components principally used in the automotive, software, and medical industries. Its stock is registered with the New York Stock Exchange and the company is subject to the normal reporting requirements of a publicly owned manufacturing concern, including the requirement of obtaining an annual audit of the Company's financial statements and internal control system. The audit is conducted by a large auditing firm.

You are the manager of the medical division of ManuTech. The financial statements of the Company are currently being audited by the external independent auditors. In the past several years, ManuTech made no significant accounting policy changes, nor did they report any extraordinary items or other unusual non-operating activities. In addition, the firm has never had disputes with external auditors regarding financial disclosures or accounting principles applied. The auditors have issued an unqualified opinion on ManuTech's financial statements in each year since the inception of the company, 


\section{Company Background (continued)}

The Company's largest selling product is an electronic component from the medical division, which you manage. This component represents approximately $50 \%$ of the Company's inventory on hand. The component involves cutting edge technology for which no industry standard has yet been developed. The technology is continually under threat of competitors creating the next generation of product, rendering the current product obsolete.

During the preparation and subsequent audit of last year's financial statements, a focus of attention was the potential obsolescence of this product. It was believed that research leading to a new generation of electronic devices was being conducted at that time by several of ManuTech's competitors. However, the competition's efforts were only at the early research and development stage at that time. While no financial disclosures were deemed appropriate for last year, this potential inventory obsolescence issue will likely be brought up again this year.

As you know, incurring a write-down due to inventory obsolescence would reduce the Company's net income. Like most companies, it is the goal of management to present income as high as possible. However, the Company also does not want to receive a qualified audit opinion, which would indicate that the auditor believes the financial statements are materially misstated. 


\section{Selected Financial Performance Indicators}

\section{Key Financial Data}

Net Sales (\$ millions)

Cost of Sales (\$ millions)

Gross Profit (\$ millions)

Net earnings (\$ millions)

Earnings per Share $(\$ / s h)$

Inventories (\$ millions)

Gross Profit Percentage (Gross Profit/Net Sales)

Gross Profit Percentage - Industry Average

Inventory Turnover Ratio (Cost of Sales/Inventory)

Inventory turnover ratio - Industry Average

Number of days in inventory

Number of days in inventory - Industry Average

$\begin{array}{cc}\begin{array}{c}\text { Current year } \\ \text { (Unaudited) }\end{array} & \begin{array}{c}\text { Prior year } \\ \text { (Audited) } \\ \$ 1,805\end{array} \\ \$ 1,768 \\ \$(1,039) & \$(1,028) \\ \$ 766 & \$ 740 \\ \$ 104 & \$ 99 \\ \$ 1.09 & \$ 1.03 \\ \$ 270 & \$ 268 \\ & \\ 42.4 & 41.9 \\ 42.6 & 41.8 \\ 3.85 & 3.84 \\ 3.95 & 3.90 \\ & \\ 95 & 95 \\ 92 & 94\end{array}$




\section{FIRST INVENTORY-RELATED ISSUES SCREEN}

\section{Inventory-Related Issues}

The following are items that were discussed within the management team with respect to a potential inventory obsolescence issue.

- The current year inventory for this component compared to last year's and two years' ago audited figures suggests that the account has not fluctuated very much.

- One of the division's VPs discovered at a trade show that the competition has designed a technologically superior product that has the potential to make ManuTech's component technologically obsolete.

- The competition is expected to have their product ready for the market very soon.

- It is an open question as to whether or not the competition will be successful at taking away ManuTech's market share as the Company's products have an established reputation in the market.

- Some customers have already pre-ordered the new device from the competition.

- The Inventory Turnover ratio for this year is similar to what it was last year and two years ago, and it's also similar to the industry average.

- The competition's new component will sell at approximately the same price point that ManuTech's component is currently selling.

- The competitor has started taking pre-orders of their component in an attempt to gain market share.

- Initial market research suggests there may be a viable third-world international market for ManuTech's component. 


\section{SECOND INVENTORY-RELATED ISSUES SCREEN}

\section{Inventory-Related Issues (continued)}

- Significant pricing changes for Manutech's component may be necessary, in which case profitability will be uncertain.

- The Days Inventory ratio for this year is similar to what it was last year and two years ago, and it's also similar to the industry average.

- ManuTech has an international marketing team that aggressively markets older technology products in developing nations around the world through existing marketing and distribution channels.

- Some sources suggest that the competition may not have done adequate testing of their new product.

- The price point at which ManuTech's component could be sold in international markets would probably not be enough to cover the product costs for the component.

- ManuTech may be able to repurpose a portion of the technology in the component to sell in other products.

- The size of the international market is debatable, so it may take up to four years to sell off the entire inventory of ManuTech's component in those markets, and whether conditions will remain stable in those markets for the duration of the four years is uncertain.

- It might be possible that ManuTech's existing component could continue to serve existing customers' needs until the commercial success and cost competitiveness of the competitor's new technology is established.

- Repurposing a portion of ManuTech's existing technology for use in other items would require an up-front investment in retooling the production process. Since profitability is uncertain, the Board of Directors may be resistant to an additional investment in the existing technology. 


\section{TRANSITION SCREEN (DEPENDENT ON CONDITION)}

Participants in the e-mail condition see the following:

The junior auditor, Ryan Miller, has sent you an e-mail. Please click the button to read.

Participants in the audio condition see the following:

The junior auditor, Ryan Miller, calls you on the phone. Please click the button to listen.

Participants in the visual condition see the following:

The junior auditor, Ryan Miller, comes to see you in person. Please click the button to see. 


\section{AUDITOR REQUEST SCREEN - E-MAIL/MORE PROFESSIONAL CONDITION}

Participants in the e-mail/more professional condition see the following:

From: Ryan Miller

Subject: Inventory

As we previously discussed, I am working on the audit of inventory and I have several questions for you.

We have concerns about a potential inventory obsolescence issue related to your product. If there were an obsolescence problem, it could indicate the need for a write-down of the inventory value to the proper market value which, of course, would reduce your net income.

To aid in our analysis, could you please provide me with information regarding any new products from other companies that are superior to your product? Please describe how this could affect sales of your product and whether you would have to sell your product at a loss.

If you believe there are factors that mitigate a potential obsolescence problem, please let me know.

Thank you, I appreciate your time. 


\section{AUDITOR REQUEST SCREEN - E-MAIL/LESS PROFESSIONAL CONDITION}

Participants in the e-mail/less professional condition see the following:

From: Ryan Miller

Subject: Inventory

As I said before, I'm doing the inventory audit and l've got some questions

We think there might be a problem with the inventory numbers. I mean there may be an inventory obsolescence problem. And if that happens we might need to write down the numbers for inventory to be at the real market value which is going to reduce your net income.

So we can look at this and figure out if there's a problem, let me know are there any new products from other companies which are better than your product? We are wondering what could this do to your product sales and could it make it that you'd have to sell your product at a loss.

If you think there are things that make you believe there's not really an obsolescence problem, let me know.

Thanks. 


\section{AUDITOR REQUEST SCREEN - AUDIO CONDITION}

Participants in the audio condition see the following. The audio track is the exact audio from the visual condition. The auditor says the same words as the e-mail condition, varying by professional tone condition.

[press play to listen]

- 00:00 1

$00: 00 \quad 4 \cdot-1111|| \mid$ 


\section{AUDITOR REQUEST SCREEN - VISUAL CONDITION}

Participants in the visual condition see the following. The picture shows the video in progress. The auditor says the same words as the e-mail condition, varying by professional tone condition.

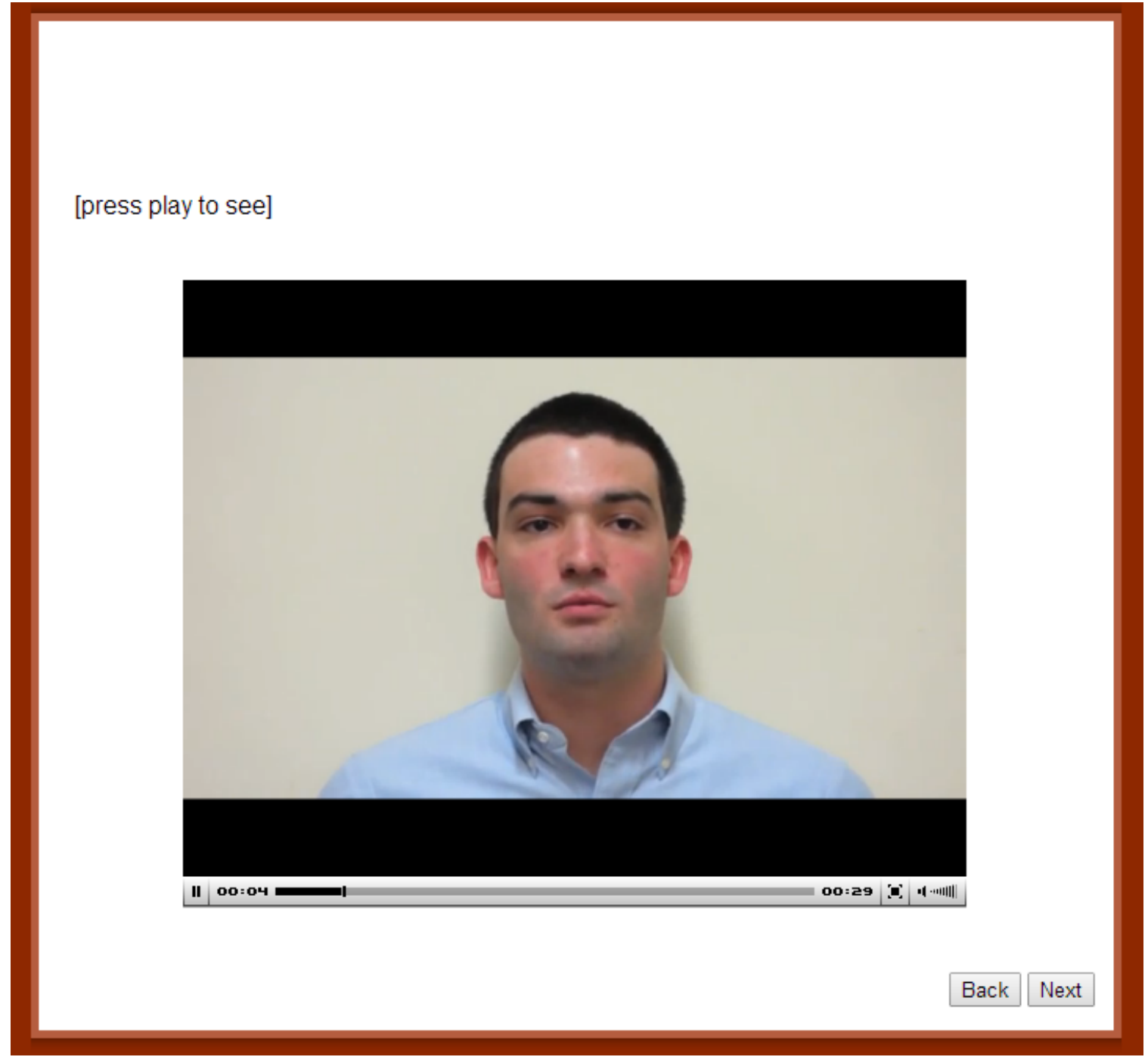




\section{RESPONSE SCREEN}

The participant types their response in the text box below. The box automatically spellchecks their response and saves the response in case they accidentally close the window. The links open the previously shown screens in separate browser windows.

In the space provided below, please compose your response to the auditor.

You can also access the information previously provided:

(clicking the following links will display the requested item in a separate browser window)

\section{Company Background}

Selected Financial Performance Indicators

Inventory-Related Issues

Please review your response carefully. When you are comfortable with the response, please click the "Next" button. 


\section{AUDITOR-PROPOSED ADJUSTMENT SCREEN - FIRST HALF}

This is the top half of the screen revealing the auditor-proposed adjustment. The second half follows on the next page.

Several days later, the lead partner from the audit team contacts ManuTech's management team and informs them that the auditors are proposing that the Company write down its inventory value by a substantial $\$ 18$ million for obsolescence related to your division's product, or $12 \%$ of the inventory balance for the component. The component is approximately half of the total inventory, therefore this write-down represents a reduction of over $6 \%$ of total inventory. The proposed adjustment reduces the Company's income for the year by $\$ 18$ million, or approximately $17 \%$ of net income.

The auditors determined this write-down based on facts provided by you and other Manutech managers, as well as from other audit procedures. They provided the following reasons for the inventory obsolescence write-down:

\section{Auditor's argument:}

The competition's product is technologically superior, could sell at the same price, and they are already accepting pre-orders. Further, ManuTech sales personnel are already reporting that customers are beginning to order the new product from the competitor.

Even though ManuTech's senior management argued that they could still sell the product in third-world international markets, the Company would have to do so at a price mark-down that likely would lead to a loss on the product. Additionally, due to uncertainty as to the size and stability of these markets, it may take up to four years to sell in those countries, if at all.

Given these concerns, the auditors propose an $\$ 18$ million write-down of inventory. 


\section{AUDITOR-PROPOSED ADJUSTMENT SCREEN - SECOND HALF}

This is the second half of the auditor-proposed adjustment screen. The links open the previous information in separate browser windows.

On the following scale, please indicate how strongly you agree or disagree with the auditor's proposal of this inventory write-down.

Strongly disagree

1

$\bigcirc$

(

ly

(1)

$\bigcirc$

$\bigcirc$
○

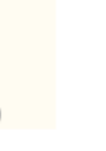

You can access the information previously provided if you wish:

(clicking the following links will display the requested item in a separate browser window)

Company Background

Selected Financial Performance Indicators

Inventory-Related Issues 


\section{NEGOTIATION RESPONSE SCREEN}

The Management Team of ManuTech wants your input about how to respond to the auditors on the inventory write-down. Please respond to their following questions:

Should ManuTech accept the auditors' proposed inventory write-down of $\$ 18,000,000$ ?

Yes

No

If no, what amount should ManuTech counterpropose to the auditor for the inventorywritedown? [Choose an amount from $\$ 0$ to $\$ 18 \mathrm{M}$ ]

$\begin{array}{lllllllllllllllllll}0 & 1 & 2 & 3 & 4 & 5 & 6 & 7 & 8 & 9 & 10 & 11 & 12 & 13 & 14 & 15 & 16 & 17 & 18\end{array}$

Amount in Smillions

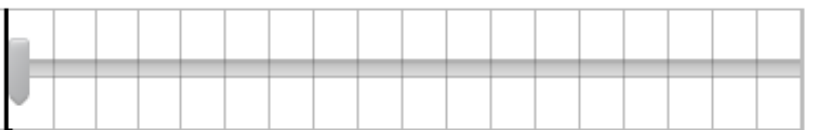

What is the maximum amount of inventory write-down you think ManuTech should be willing to accept? [Choose an amount from $\$ 0$ to $\$ 18 \mathrm{M}$ ]

$\begin{array}{lllllllllllllllllll}0 & 1 & 2 & 3 & 4 & 5 & 6 & 7 & 8 & 9 & 10 & 11 & 12 & 13 & 14 & 15 & 16 & 17 & 18\end{array}$

Amount in \$millions

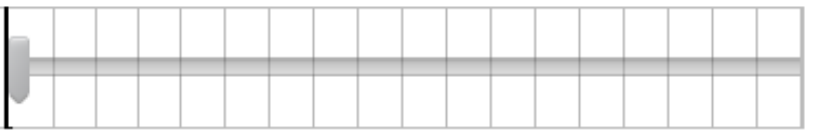




\section{POST-EXPERIMENTAL QUESTIONS - AFFECT QUESTIONS}

You are almost done. Thank you very much for your assistance.

On the following few pages, there will be some questions about your experience. This will be followed by a brief survey and then the study will be complete.

On the following scale, please indicate to what extent Ryan Miller (the junior auditor) made you feel:

\begin{tabular}{l|ccccccccccc} 
& $\begin{array}{c}\text { Not at } \\
\text { all } \\
0\end{array}$ & 1 & 2 & 3 & 4 & 5 & 6 & 7 & 8 & 9 & $\begin{array}{c}\text { Very } \\
\text { much } \\
10\end{array}$ \\
\hline Angry & 0 & 0 & 0 & 0 & 0 & 0 & 0 & 0 & 0 & 0 & 0 \\
Annoyed & 0 & 0 & 0 & 0 & 0 & 0 & 0 & 0 & 0 & 0 & 0 \\
Sad & 0 & 0 & 0 & 0 & 0 & 0 & 0 & 0 & 0 & 0 & 0 \\
Happy & 0 & 0 & 0 & 0 & 0 & 0 & 0 & 0 & 0 & 0 & 0 \\
Frustrated & 0 & 0 & 0 & 0 & 0 & 0 & 0 & 0 & 0 & 0 & 0
\end{tabular}

On the same scale, please indicate to what extent the auditors (the entire team, including the lead audit partner) made you feel:

\begin{tabular}{l|ccccccccccc} 
& $\begin{array}{c}\text { Not at } \\
\text { all } \\
0\end{array}$ & 1 & 2 & 3 & 4 & 5 & 6 & 7 & 8 & 9 & $\begin{array}{c}\text { Very } \\
\text { much } \\
10\end{array}$ \\
\hline Angry & 0 & 0 & 0 & 0 & 0 & 0 & 0 & 0 & 0 & 0 & 0 \\
Annoyed & 0 & 0 & 0 & 0 & 0 & 0 & 0 & 0 & 0 & 0 & 0 \\
Sad & 0 & 0 & 0 & 0 & 0 & 0 & 0 & 0 & 0 & 0 & 0 \\
Happy & 0 & 0 & 0 & 0 & 0 & 0 & 0 & 0 & 0 & 0 & 0 \\
Frustrated & 0 & 0 & 0 & 0 & 0 & 0 & 0 & 0 & 0 & 0 & 0
\end{tabular}


For each of the following, select the number that most closely represents your level of agreement with the statement:

\begin{tabular}{|c|c|c|c|c|c|c|c|c|c|}
\hline & $\begin{array}{c}\text { Strongly } \\
\text { disagree } \\
1\end{array}$ & 2 & 3 & 4 & $\begin{array}{c}\text { Neither } \\
\text { agree } \\
\text { nor } \\
\text { disagree } \\
5\end{array}$ & 6 & 7 & 8 & $\begin{array}{c}\text { Strongly } \\
\text { agree } \\
9\end{array}$ \\
\hline $\begin{array}{l}\text { I found Ryan to be } \\
\text { likable. }\end{array}$ & $\bigcirc$ & 0 & $\bigcirc$ & 0 & $\bigcirc$ & ○ & O & $\bigcirc$ & $\bigcirc$ \\
\hline Ryan is intelligent. & 0 & 0 & 0 & 0 & 0 & 0 & 0 & 0 & 0 \\
\hline Ryan is competent. & $\bigcirc$ & 0 & $\bigcirc$ & 0 & $\bigcirc$ & 0 & $\bigcirc$ & $\bigcirc$ & $\bigcirc$ \\
\hline Ryan is credible. & 0 & 0 & 0 & 0 & 0 & 0 & 0 & 0 & 0 \\
\hline $\begin{array}{l}\text { The auditors are } \\
\text { competent. }\end{array}$ & $\bigcirc$ & 0 & $\bigcirc$ & 0 & 0 & 0 & O & $\bigcirc$ & $\bigcirc$ \\
\hline $\begin{array}{l}\text { The auditors are } \\
\text { credible. }\end{array}$ & $\bigcirc$ & 0 & 0 & 0 & 0 & O & O & O & ○ \\
\hline
\end{tabular}


POST-EXPERIMENTAL QUESTIONS - PERCEPTIONS OF RYAN AND THE AUDITORS - SECOND SCREEN

For each of the following, select the number that most closely represents your level of agreement with the statement:

\begin{tabular}{|c|c|c|c|c|c|c|c|c|c|}
\hline & $\begin{array}{c}\text { Strongly } \\
\text { disagree } \\
1\end{array}$ & 2 & 3 & 4 & $\begin{array}{c}\text { Neither } \\
\text { agree } \\
\text { nor } \\
\text { disagree } \\
5\end{array}$ & 6 & 7 & 8 & $\begin{array}{l}\text { Strongly } \\
\text { agree } \\
9\end{array}$ \\
\hline $\begin{array}{l}\text { Responding well to Ryan was } \\
\text { important to me. }\end{array}$ & 0 & 0 & 0 & 0 & 0 & 0 & 0 & 0 & 0 \\
\hline $\begin{array}{l}\text { I felt obligated to answer Ryan's } \\
\text { questions thoroughly. }\end{array}$ & 0 & 0 & 0 & 0 & 0 & 0 & 0 & 0 & 0 \\
\hline $\begin{array}{l}\text { Ryan's questions affected my } \\
\text { opinion about the inventory } \\
\text { obsolescence write-down. }\end{array}$ & 0 & 0 & 0 & 0 & 0 & 0 & 0 & $\bigcirc$ & 0 \\
\hline Ryan was disrespectful. & 0 & 0 & 0 & 0 & 0 & 0 & 0 & 0 & 0 \\
\hline $\begin{array}{l}\text { I would want to work with Ryan } \\
\text { again. }\end{array}$ & 0 & 0 & 0 & 0 & 0 & 0 & 0 & 0 & 0 \\
\hline $\begin{array}{l}\text { I would want to work with this audit } \\
\text { firm again. }\end{array}$ & 0 & 0 & 0 & 0 & 0 & 0 & 0 & 0 & 0 \\
\hline $\begin{array}{l}\text { I felt the auditors' proposed } \\
\text { reduction of the inventory balance } \\
\text { was unfair. }\end{array}$ & 0 & 0 & $\bigcirc$ & 0 & $\bigcirc$ & 0 & 0 & 0 & 0 \\
\hline
\end{tabular}


POST-EXPERIMENTAL QUESTIONS - PROFESSIONALISM AND AGE

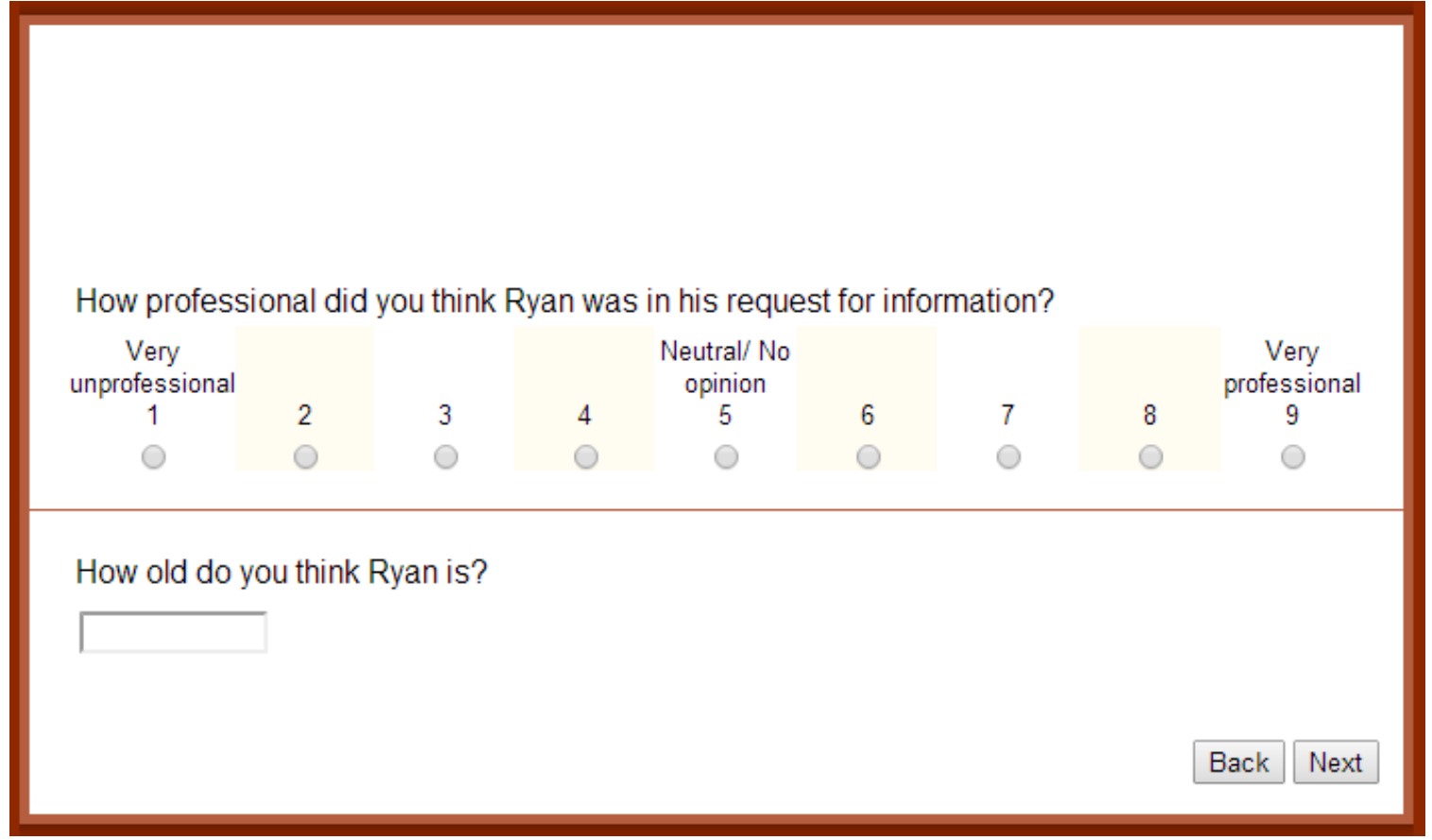




\section{POST-EXPERIMENTAL QUESTIONS - TECHNOLOGY USE - FIRST HALF OF SCREEN}

This is the first half of this screen. The second half follows on the next page.

On this and the next screen, please respond to the following survey questions:

Using the following scale, how often do you engage in each of these activities?

\begin{tabular}{|c|c|c|c|c|c|c|}
\hline & $\begin{array}{l}\text { Never } \\
0\end{array}$ & 1 & 2 & 3 & 4 & $\begin{array}{c}\text { Very often } \\
5\end{array}$ \\
\hline $\begin{array}{l}\text { Sending and receiving text } \\
\text { messages on a cell phone for } \\
\text { professional purposes. }\end{array}$ & $\bigcirc$ & $\bigcirc$ & O & $\bigcirc$ & O & $\bigcirc$ \\
\hline $\begin{array}{l}\text { Sending and receiving text } \\
\text { messages on a cell phone to } \\
\text { communicate with friends. }\end{array}$ & $\bigcirc$ & $\bigcirc$ & 0 & 0 & O & $\bigcirc$ \\
\hline $\begin{array}{l}\text { Using instant messaging (on a } \\
\text { computer) for professional purposes. }\end{array}$ & $\bigcirc$ & O & 0 & 0 & O & $\bigcirc$ \\
\hline $\begin{array}{l}\text { Using instant messaging (on a } \\
\text { computer) to communicate with } \\
\text { friends. }\end{array}$ & $\bigcirc$ & $\bigcirc$ & O & O & O & $\bigcirc$ \\
\hline Using Twitter. & $\bigcirc$ & $\bigcirc$ & O & O & 0 & $\bigcirc$ \\
\hline Using Facebook. & 0 & $\bigcirc$ & O & O & O & $\bigcirc$ \\
\hline
\end{tabular}




\section{POST-EXPERIMENTAL QUESTIONS - TECHNOLOGY USE - SECOND HALF OF SCREEN}

This is the second half of this screen. As participants enter numbers, the total is computed automatically and the screen cannot advance until the responses total to $100 \%$ for each question.

Choosing from the following communication methods, what percentage of the time do you use each method to communicate with others in a professional context? (total must sum to $100 \%)$

Face-to-face (in person)

Video (e.g., Skype)

0

Phone (land-line or cell phone)

E-mail

Instant message or text message

Total

Again, choosing from the following communication methods, what percentage of the time would you prefer to receive a request for information via each of the following methods in a professional context? (total must sum to $100 \%$ )

Face-to-face (in person)

Video (e.g., Skype)

Phone (land-line or cell phone)

E-mail

Instant message or text message

Total
0

0

0

0

0

0 


\section{POST-EXPERIMENTAL QUESTIONS - SURVEY, INCLUDING POWER DISTANCE QUESTIONS - FIRST HALF OF SCREEN}

This is the first half of this screen. The second half follows on the next page.

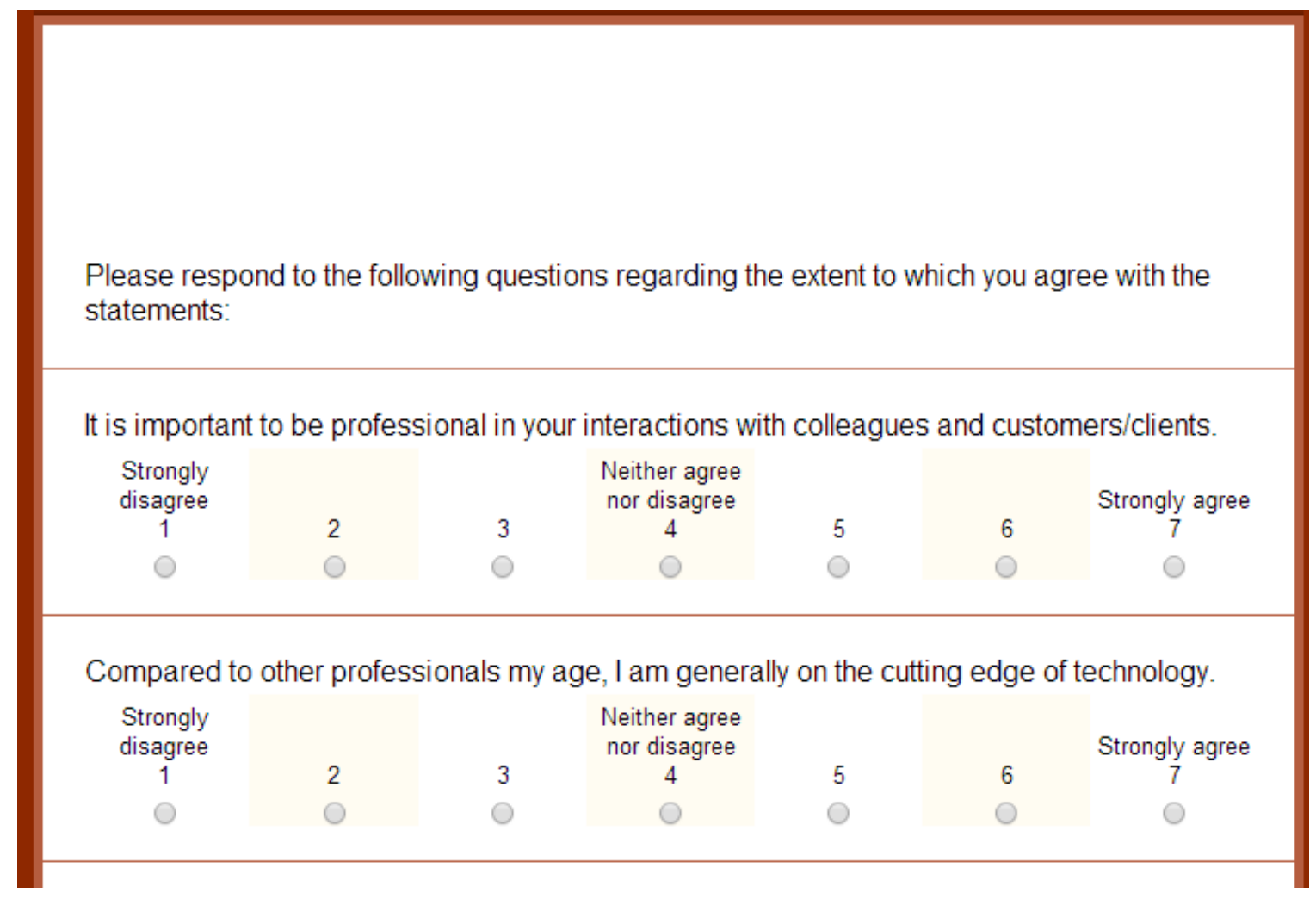




\section{POST-EXPERIMENTAL QUESTIONS - SURVEY, INCLUDING POWER DISTANCE QUESTIONS - SECOND HALF OF SCREEN}

This is the second half of this screen.

In my company or organization, subordinates are expected to:

Obey their boss

without

question

1

2

3

4

5

Question their

boss when in

$\bigcirc$

○

$\bigcirc$

○

O

disagreement

7

In my company or organization, a person's influence is based primarily on:

One's ability \&

contribution to

the organization

23

4

4

$\bigcirc$

$\bigcirc$

(1)

0

The authority of one's position

In general, I believe subordinates should:

Obey their boss

without

question

1

$2 \quad 3$

0

$\bigcirc$

4

(1)

5

6

Question their

boss when in

disagreement

7

○

In general, I believe rank and position in an organization's hierarchy should have special privileges:

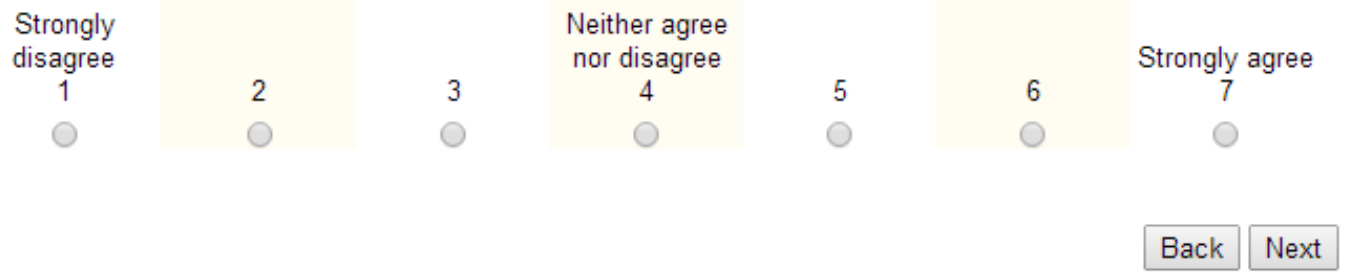




\section{DEMOGRAPHIC INFORMATION SCREEN}

Finally, please provide the following information:

How many years of business experience do you have?

How many years of managerial experience do you have?

What is your professional title? If you are not currently employed, what is the last title you held?

In what industry do you work?

What is your gender?

Female

Male

What is your age? 


\section{BIBLIOGRAPHY}

American Institute of Certified Public Accounts (AICPA). 2012. CPA Vision Project. Available at: http://www.aicpa.org/research/cpahorizons2025/cpavisionproject/ downloadabledocuments/cpavisionproject_finalreport.pdf.

Bame-Aldred, C. W., and T. Kida. 2007. A comparison of auditor and client initial negotiation positions and tactics. Accounting, Organizations and Society 32 (6): 497511.

Bennett, G. B., and R. C. Hatfield. 2013. The effect of the social mismatch between staff auditors and client management on the collection of audit evidence. The Accounting Review 88 (1): 31-50.

Brauer, M., and P. Chekroun. 2005. The relationship between perceived violation of social norms and social control: Situational factors influencing the reaction to deviance. Journal of Applied Social Psychology 35 (7): 1519-39.

Brazel, J. F., C. P. Agoglia, and R. C. Hatfield. 2004. Electronic versus face-to-face review: The effects of alternative forms of review on auditors' performance. The Accounting Review 79 (4): 949-66.

Brazel, J. F., K. L. Jones, and M. F. Zimbelman. 2009. Using nonfinancial measures to assess fraud risk. Journal of Accounting Research 47 (5): 1135-66.

Brown-Liburd, H. L., and A. M. Wright. 2011. The effect of past client relationship and strength of the audit committee on auditor negotiations. Auditing: A Journal of Practice \& Theory 30 (4): 51-69.

Buckless, F. A., and S. P. Ravenscroft. 1990. Contrast coding: A refinement of ANOVA in behavioral analysis. The Accounting Review 65 (4): 933-45.

Burgoon, J. K., L. A. Stern, and L. Dillman. 1995. Interpersonal Adaptation: Dyadic Interaction Patterns. Cambridge: Cambridge University Press.

Byron, K. 2008. Carrying too heavy a load? The communication and miscommunication of emotion by email. Academy of Management Review 33 (2): 309-27.

Calvert, V., and R. Kurji. 2012. Service-learning in a managerial accounting course: Developing the 'soft' skills. American Journal of Economics and Business Administration 4 (1): 5-12.

Carr, C. T., and C. Stefaniak. 2012. Sent from my iPhone: The medium and message as cues of sender professionalism in mobile telephony. Journal of Applied Communication Research 40 (4): 403-24.

Chaiken, S., R. Giner-Sorolla, and S. Chen. 1996. Beyond accuracy: Defense and impression motives in heuristic and systematic information processing. In The Psychology of Action: Linking Cognition and Motivation to Behavior. Edited by P. M. Gollwitzer and J. A. Bargh, 553-78. New York: Guilford Press. 
Cheney, G., and K. L. Ashcraft. 2007. Considering "the professional" in communication studies: Implications for theory and research within and beyond the boundaries of organizational communication. Communication Theory 17 (2): 146-75.

Cheshin, A., A. Rafaeli, and N. Bos. 2011. Anger and happiness in virtual teams: Emotional influences of text and behavior on others' affect in the absence of nonverbal cues. Organizational Behavior and Human Decision Processes 116 (1): 2-16.

Cialdini, R. B., and N. J. Goldstein. 2004. Social influence: Compliance and conformity. Annual Review of Psychology 55 (1): 591-621.

Claypool, H. M., D. M. Mackie, T. Garcia-Marques, A. McIntosh, and A. Udall. 2004. The effects of personal relevance and repetition on persuasive processing. Social Cognition 22 (3): 310-35.

Cohen, J. R., G. Krishnamoorthy, and A. M. Wright. 2005. Dynamic Data: Corporate governance and auditors' evaluation of accounting estimates. Issues in Accounting Education 20 (1): 119-28.

Clor-Proell, S. M. 2009. The Effects of Expected and Actual Accounting Choices on Judgments and Decisions. The Accounting Review 84 (5): 1465-93.

Dixon, J., C. Belnap, C. Albrecht, and K. Lee. 2010. The importance of soft skills. Corporate Finance Review 14 (6): 35-38.

Daft, R. L., and R. H. Lengel. 1986. Organizational information requirements, media richness and structural design. Management Science 32 (5): 554-71.

Eagly, A. H. 2007. In defence of ourselves: The effects of defensive processing on attitudinal phenomena. In The Scope of Social Psychology: Theory and Applications: Essays in Honour of Wolfgang Stroebe. Edited by M. Hewstone, H. A. W. Schut, J. B. De Wit, K. Van Den Bos, and M. S. Stroebe, 65-83. New York, NY: Psychology Press.

Elliott, W. B., F. D. Hodge, and L. M. Sedor. 2012. Using online video to announce a restatement: Influences on investment decisions and the mediating role of trust. The Accounting Review 87 (2): 513-35.

Ernst \& Young. 2008. The generation gap: The real story at Ernst \& Young. Ernst \& Young Generations Study Findings.

Fanning, K., and M. D. Piercey. 2013. Internal auditors’ use of interpersonal likability, arguments, and accounting information in a corporate governance setting. Working Paper, University of Illinois at Urbana-Champaign and University of MassachusettsAmherst.

Ferran, C., and S. Watts. 2008. Videoconferencing in the field: A heuristic processing model. Management Science 54 (9): 1565-78.

Field, A. P. 2013. Discovering statistics using IBM SPSS statistics. 4th ed. London: SAGE. 
Fischer, P., J. Fischer, S. Weisweiler, and D. Frey. 2010. Selective exposure to information: How different modes of decision making affect subsequent confirmatory information processing. British Journal of Social Psychology 49 (4): 871-81.

Fischer, P., T. Greitemeyer, and D. Frey. 2007. Ego depletion and positive illusions: Does the construction of positivity require regulatory resources? Personality and Social Psychology Bulletin 33 (9): 1306-21.

Garcia-Marques, T., and D. M. Mackie. 2001. The feeling of familiarity as a regulator of persuasive processing. Social Cognition 19 (1): 9-34.

Gibbins, M., S. A. McCracken, and S. E. Salterio. 2007. The chief financial officer's perspective on auditor-client negotiations. Contemporary Accounting Research 24 (2): 387-422.

Gibbins, M., S. Salterio, and A. Webb. 2001. Evidence about auditor-client management negotiation concerning client's financial reporting. Journal of Accounting Research 39 (3): 535-63.

Hatfield, R. C., R. W. Houston, C. M. Stefaniak, and S. Usrey. 2010. The effect of magnitude of audit difference and prior client concessions on negotiations of proposed adjustments. The Accounting Review 85 (5): 1647-68.

Hayes, A. F., and K. Krippendorff. 2007. Answering the call for a standard reliability measure for coding data. Communication Methods and Measures 1 (1): 77-89.

Hayes, A. F. 2013. Introduction to Mediation, Moderation, and Conditional Process Analysis: A Regression-Based Approach. Methodology in the Social Sciences. New York: The Guilford Press.

Hirst, D. E., and L. Koonce. 1996. Audit analytical procedures: A field investigation. Contemporary Accounting Research 13 (2): 457-86.

House, R. J., P. J. Hanges, M. Javidan, P. W. Dorfman, and V. Gupta, eds. 2004. Culture, leadership, and organizations: The GLOBE study of 62 societies. Thousand Oaks, Calif: Sage Publications.

Jackson, D. 2012. Business undergraduates' perceptions of their capabilities in employability skills: Implications for industry and higher education. Industry and Higher Education 26 (5): 345-56.

Jessmer, S. L., and D. Anderson. 2001. The effect of politeness and grammar on user perceptions of electronic mail. North American Journal of Psychology 3 (2): 331-46.

Jonas, E., S. Schulz-Hardt, and D. Frey. 2005. Giving advice or making decisions in someone else's place: The influence of impression, defense, and accuracy motivation on the search for new information. Personality and Social Psychology Bulletin 31 (7): 977-90.

Jones, C. G. 2011. Written and computer-mediated accounting communication skills: an employer perspective. Business Communication Quarterly 74 (3): 247-71. 
Kachelmeier, S. J., and M. G. Williamson. 2010. Attracting creativity: The initial and aggregate effects of contract selection on creativity-weighted productivity. The Accounting Review 85 (5): 1669-91.

Kaplan, S. E., K. R. Pope, and J. A. Samuels. 2011. An examination of the effect of inquiry and auditor type on reporting intentions for fraud. Auditing 30 (4): 29-49.

King, R. C., and W. Xia. 1997. Media appropriateness: Effects of experience on communication media choice. Decision Sciences 28 (4): 877-910.

Kramer, M. W., and J. A. Hess. 2002. Communication rules for the display of emotions in organizational settings. Management Communication Quarterly 16 (1): 66-80.

Lancaster, L. C., and D. Stillman. 2010. The M-factor: How the Millennial Generation is Rocking the Workplace. 1st ed. New York: HarperBusiness.

Lee, C.-C., and R. B. Welker. 2007. The effect of audit inquiries on the ability to detect financial misrepresentations. Behavioral Research in Accounting 19: 161-78.

Levine, T. R., L. N. Anders, J. Banas, K. L. Baum, K. Endo, A. D. S. Hu, and N. C. H. Wong. 2000. Norms, expectations, and deception: A norm violation model of veracity judgments. Communication Monographs 67 (2): 123-37.

Libby, R., R. Bloomfield, and M. W. Nelson. 2002. Experimental research in financial accounting. Accounting, Organizations and Society 27 (8): 775-810.

Liu, G. 2012. Gathering evidence through enquiry: A process improvement focus. Behavioral Research in Accounting 24 (2): 153-75.

Lynch, A. L., U. S. Murthy, and T. J. Engle. 2009. Fraud brainstorming using computermediated communication: The effects of brainstorming technique and facilitation. The Accounting Review 84 (4): 1209-32.

May, C. A., and G. S. May. 2012. Effective writing: A handbook for accountants. 9th ed. Boston: Prentice Hall.

Messier, W. F., S. M. Glover, and D. F. Prawitt. 2012. Auditing \& Assurance Services: A Systematic Approach. 8th ed. New York, NY: McGraw-Hill/Irwin.

Neuendorf, K. A. 2002. The Content Analysis Guidebook. Thousand Oaks, Calif: Sage Publications.

Nöteberg, A., T. L. Benford, and J. E. Hunton. 2003. Matching electronic communication media and audit tasks. International Journal of Accounting Information Systems 4 (1): 27-55.

Nöteberg, A., and J. E. Hunton. 2005. Client inquiry via electronic communication media: Does the medium matter? Advances in Accounting Behavioral Research 8: 87112.

Peecher, M. E., and I. Solomon. 2001. Theory and experimentation in studies of audit judgments and decisions: Avoiding common research traps. International Journal of Auditing 5 (3): 193-203.

Perreault, S., and T. Kida. 2011. The relative effectiveness of persuasion tactics in auditor-client negotiations. Accounting, Organizations and Society 36 (8): 534-47. 
Perreault, S. J., T. Kida, and M. D. Piercey. 2013. The relative effectiveness of simultaneous versus sequential negotiation strategies in auditor-client negotiations. Working Paper, Providence College and University of Massachusetts-Amherst.

Piercey, M. D. 2011. Documentation requirements and quantified versus qualitative audit risk assessments. Auditing: A Journal of Practice \& Theory 30 (4): 223-48.

Postmes, T., R. Spears, and M. Lea. 2000. The formation of group norms in computermediated communication. Human Communication Research 26 (3): 341-71.

Ricchiute, D. N. 1999. The effect of audit seniors' decisions on working paper documentation and on partners' decisions. Accounting, Organizations and Society 24 (2): 155-71.

Salterio, S. E. 2012. Fifteen years in the trenches: Auditor-client negotiations exposed and explored. Accounting \& Finance 52: 233-86.

Sanchez, M. H., C. P. Agoglia, and R. C. Hatfield. 2007. The effect of auditors' use of a reciprocity-based strategy on auditor-client negotiations. The Accounting Review 82 (1): 241-63.

Scott, C. R., and C. E. Timmerman. 2005. Relating computer, communication, and computer-mediated communication apprehensions to new communication technology use in the workplace. Communication Research 32 (6): 683-725.

Sheeran, P. 2002. Intention-behavior relations: A conceptual and empirical review. European Review of Social Psychology 12 (1): 1-36.

Short, J. A. 1974. Effects of medium of communication on experimental negotiation. Human Relations 27 (3): 225-34.

Suh, K. S. 1999. Impact of communication medium on task performance and satisfaction: An examination of media-richness theory. Information \& Management 35 (5): 295312.

Sussman, S. W., and W. S. Siegal. 2003. Informational influence in organizations: An integrated approach to knowledge adoption. Information Systems Research 14 (1): 4765.

Swaab, R. I., A. D. Galinsky, V. Medvec, and D. A. Diermeier. 2012. The communication orientation model: Explaining the diverse effects of sight, sound, and synchronicity on negotiation and group decision-making outcomes. Personality and Social Psychology Review 16 (1): 25-53.

Tan, H.-T., and K. T. Trotman. 2010. Effects of the timing of auditors' income-reducing adjustment concessions on financial officers' negotiation judgments. Contemporary Accounting Research 27 (4): 1207-39.

Tetlock, P. E., L. Skitka, and R. Boettger. 1989. Social and cognitive strategies for coping with accountability: Conformity, complexity, and bolstering. Journal of Personality and Social Psychology 57 (4): 632-40.

Trompeter, G., and A. Wright. 2010. The world has changed - Have analytical procedure practices? Contemporary Accounting Research 27 (2): 669-700. 
Waner, K. K. 1995. Business communication competencies needed by employees as perceived by business faculty and business professionals. Business Communication Quarterly 58 (4): 51-56.

Wang, K. J., and B. M. Tuttle. 2009. The impact of auditor rotation on auditor-client negotiation. Accounting, Organizations and Society 34 (2): 222-43.

White, C. H. 2008. Expectancy violations theory and interaction adaptation theory. In Engaging Theories in Interpersonal Communication: Multiple Perspectives. Edited by L. A. Baxter and D. O. Braithwaite, 189-202. Los Angeles: Sage Publications.

Yip-Ow, J., and H.-T. Tan. 2000. Effects of the preparer's justification on the reviewer's hypothesis generation and judgment in analytical procedures. Accounting, Organizations and Society 25 (2): 203-15. 